UNIVERSITY OF CALIFORNIA - COLLEGE OF AGRICULTURE AGRICULTURAL EXPERIMENT STATION BERKELEY, CALIFORNIA

\title{
INCREASING VALLEY QUAIL IN CALIFORNIA
}

JOHN T. EMLEN, JR. and BEN GLADING

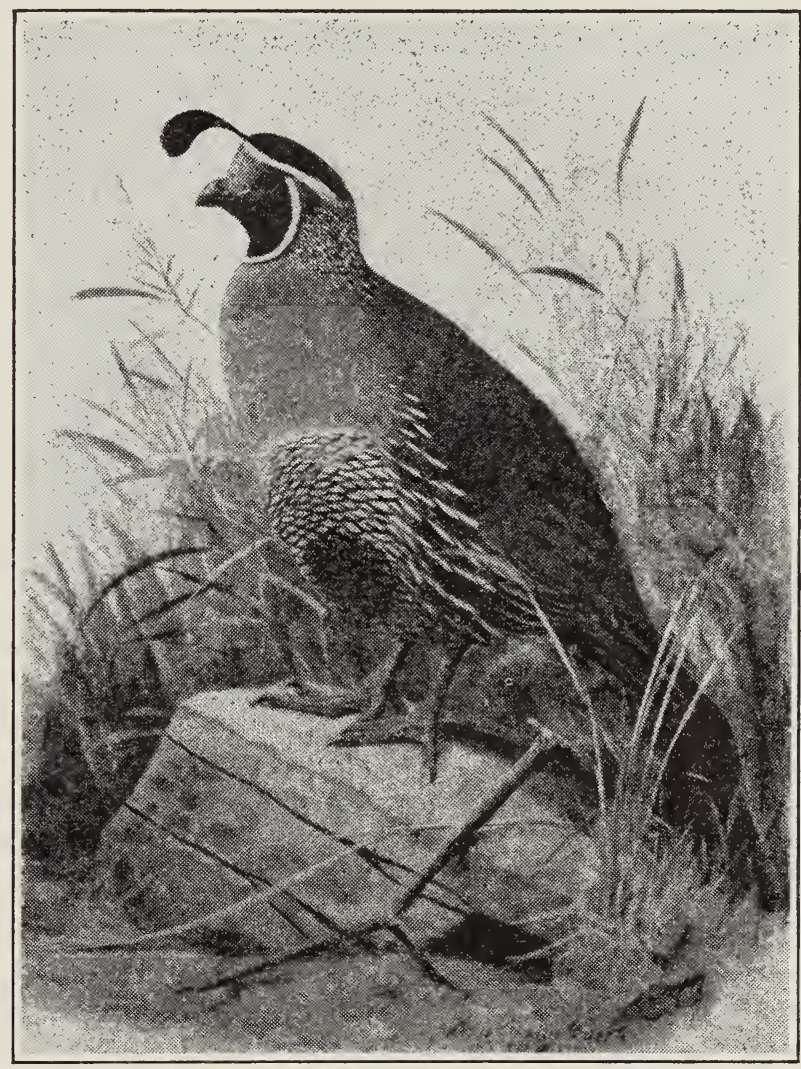

CALIFORNIA VALLEY QUAIL

BULLETIN 695

November, 1945 


\section{CONTENTS}

PAGE

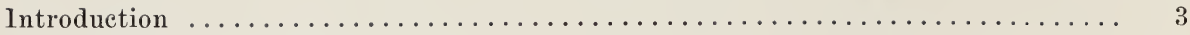

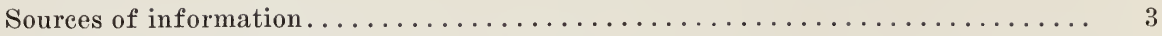

Principles and methods of quail management. . . . . . . . . . . . . . . . .

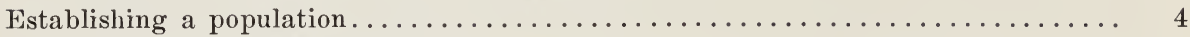

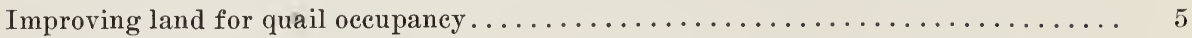

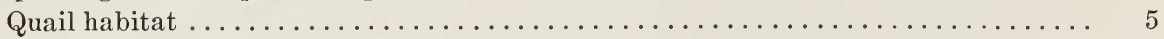

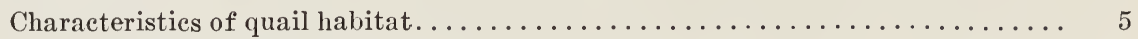

Quail habitats of California........................... 8

Detecting habitat deficiencies........................... 12

Laying the management plans. . . . . . . . . . . . . . . . . . . . . . 13

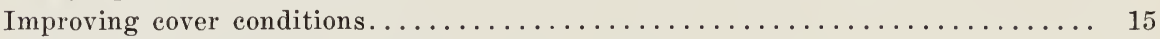

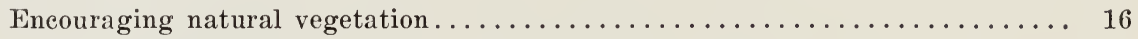

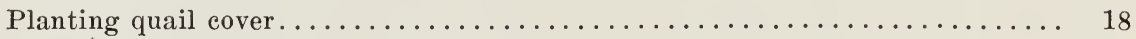

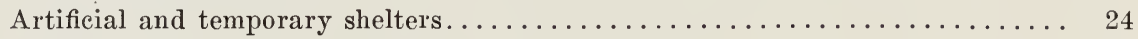

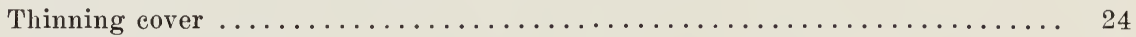

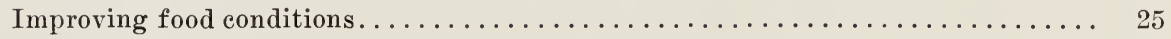

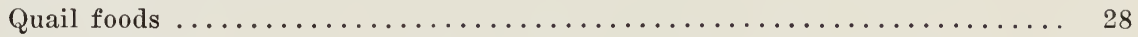

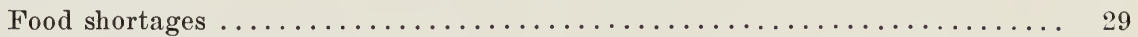

Encouraging natural food plants............................ 29

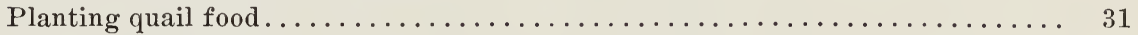

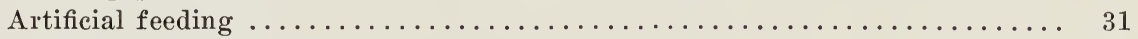

Improving water conditions. . . . . . . . . . . . . . . . . . . . . . . 34

Water requirements ................................ 34

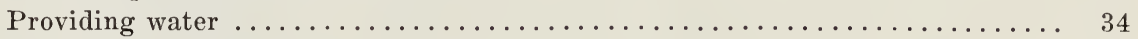

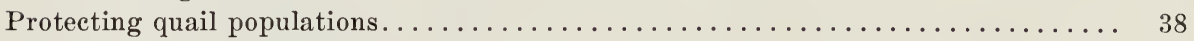

Predators ................................... 40

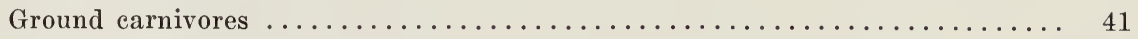

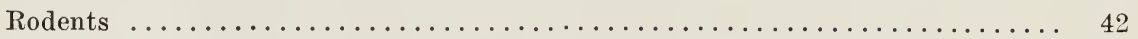

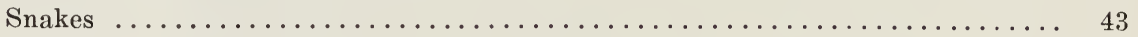

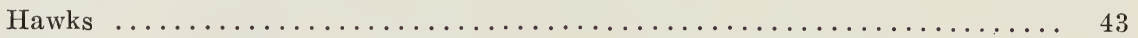

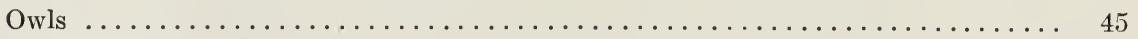

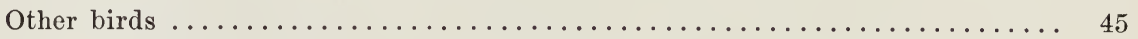

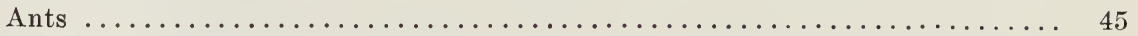

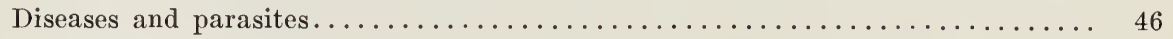

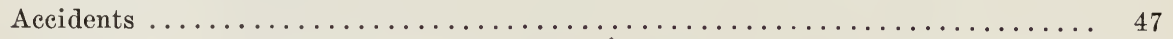

Hunting ...................................... 48

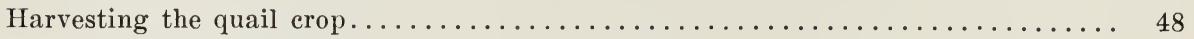

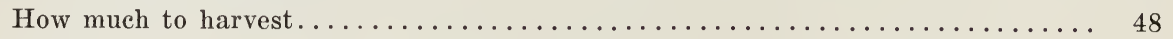

How to harvest. ................................. 49

How to record the harvest............................ 50

Hunting privileges and rights........................... 53

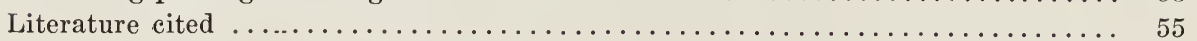




\section{INCREASING VALLEY QUAIL IN CALIFORNIA}

JOHN T. EMLEN, JR. ${ }^{2}$ and BEN GLADING ${ }^{3}$

\section{INTRODUCTION}

The valuey QuaIL, ${ }^{4}$ California's state bird, is one of the most popular wild creatures on the farmlands, ranches, and waste areas where it is found. Almost everyone is attracted by its beauty of plumage, pleasing call notes, and friendly behavior. To the California sportsman it is the king of upland game birds, calling forth his best in alertness and marksmanship.

Quail have been driven from some areas that they formerly inhabited and are less common than they might be in many others. Ranchers who have few or none on their properties often desire to encourage and foster a quail pcpulation in their fields and around their homes. Sportsmen spend much time speculating on ways to protect and increase quail on their favorite hunting grounds.

Existing knowledge on the management of valley quail is still far from complete. Such topics as the relation of food abundance to population density and the effect of intensive predator control on quail numbers are poorly understood. Knowledge of the diseases of quail is almost lacking as far as practical game management is concerned. Indeed, there is no single phase of quail management on which the authors would venture a final answer. Enough information has been accumulated, however, to warrant publication of a practical guide to some tested practices useful to ranchers, sportsmen, and bird lovers who are interested in building up quail populations.

\section{SOURCES OF INFORMATION}

The authors have drawn from their experience during eight years of intensive study of valley quail on farms, range lands, and desert areas of California ; from the writings of other students of game problems; and from the unpublished observations of many ranchers, sportsmen, and game specialists who have contributed valuable information and suggestions. In particular, they acknowledge the scientific contributions of the United States Fish and Wildlife Service, the United States Soil Conservation Service, the United States Forest Service, the University of California College of Agriculture, and the California Division of Fish and Game. Most of the work of the authors was done under the auspices of the last three of these agencies. ${ }^{5}$

\footnotetext{
${ }^{1}$ Received for publication March 16, 1945.

${ }^{2}$ Assistant Professor of Zoölogy and Assistant Zoölogist in the Experiment Station; resigned July $27,1943$.

${ }^{3}$ Economic Biologist, California Division of Fish and Game.

${ }^{4}$ The frontispiece shows a male valley quail (Lophortyx californica), from a painting by Louis Agassiz Fuertes made for the California Division of Fish and Game.

5 From 1935 to 1943 , Emlen investigated the life history and management of valley quail under the auspices of the California Agricultural Experiment Station. From 1936 to 1941 , Glading made similar studies for the Coöperative Valley Quail Management Committee, a joint project of the U. S. Forest Service, U. S. Fish and Wildlife Service, University of California College of Agriculture, and California Division of Fish and Game. From 1941 to date,
} 


\section{PRINCIPLES AND METHODS OF QUAIL MANAGEMENT}

Valley quail are sedentary, and their management is a problem comparable in many respects to the management of an agricultural crop. The program involves three steps: (1) establishing a breeding stock, (2) aiding and protecting this stock during its development, and (3) harvesting the surplus.

Establishing a breeding stock is seldom difficult in California; if the area is at all suitable, there are usually at least a few quail present. Given a small population as seed stock and an adequate tract of land, nature can produce a bountiful supply of new quail every summer.

The nurture and care of this stock constitute the second or cultural step. This calls for two lines of action : first, the provision of living space or habitat attractive and adequate for the special life requirements of quail; second, protection against enemies, accidents, and overshooting. The first of these, commonly known as habitat management, is of fundamental significance. Only through habitat improvement, by providing more and better living space for the quail, can one establish and maintain an increased population on anything like a stable basis. Protection is a valuable supplementary measure, and the two should be practiced together. The basic breeding population is determined by the habitat and may generally be increased by habitat improvement; the harvestable surplus, determined by the size of the breeding stock, may be conserved for limited periods through protection against enemies and accidents.

The harvesting of the quail crop, when contemplated, must be considered as an integral part of the program. Measurements of a quail population by censuses and records of the hunting-season kill provide the basis for determining just how many birds may be safely taken from an area. A safe annual harvest of 20 to 30 quail (and, with special effort, up to 150) per hundred acres of managed range, is gratifying compensation for time and money expended.

\section{ESTABLISHING A POPULATION}

It is rarely necessary to establish or supplement a quail population by introducing new stock. Quail occur on all or nearly all suitable areas in California in numbers approximating the ability of the existing environment to support them. Their natural reproductive powers, furthermore, are ample to correct quickly any temporary setback caused by local catastrophe or overshooting. Thus their scarcity or absence is almost invariably due to unfavorable living conditions rather than to any reproductive deficiency. Dumping birds into an inadequate habitat is like pouring water into a leaky bucket. Sportsmen will do well to turn their primary efforts to repairing the bucket.

The argument that new birds bring vigor into a population by reducing inbreeding is without proof. Wild individuals regularly move about from covey to covey during the year. This is particularly true of surplus males in the nesting season. Thus, serious inbreeding is almost inconceivable under natural con-

Glading has done similar work for the California Division of Fish and Game in coöperation with the Federal Aid to Wildlife Restoration, Project California 6-R.

Dr. Carl B. Wolf, Santa Ana Botanic Garden, Anaheim, California, gave generous help in the preparation of table 2 and in parts of the section "Improving Cover Conditions."

Grateful acknowledgment is due Dr. Tracy I. Storer, Division of Zoölogy, College of Agriculture, University of California, for initiating and guiding the program of study of quail by the authors, and for editorial help in the preparation of this publication. 
ditions. Game-farm birds are rarely as robust as wild quail and often carry diseases acquired in crowded pens. The liberation of such birds is a hazard rather than a benefit to a wild population.

The introduction of new birds may be desirable where an isolated quail habitat has never been populated or has been depopulated by some local catastrophe, or where a population is regularly overshot. The first situation rarely occurs in valley quail range in California; the second is sometimes encountered on club properties and around centers of population. A temporary supply of shootable birds may be had by a release just before the hunting season ; introducing new birds, however, is an expensive procedure, and is recommended only after everything possible has been done to encourage natural reproduction and survival. If and when necessary, quail may be obtained from private game breeders or from the state game farms. Of recent years a limited supply of wild-trapped birds has been available from the Division of Fish and Game (17).

\section{IMPROVING LAND FOR QUAIL OCCUPANCY}

Quail, like livestock, cannot be crowded into inferior range. Cattle or sheep rapidly lose condition when held on deteriorating pasture. Quail, being unrestricted by fences, simply move on to better locations or die; thus the number residing on an area generally indicates the quality of the habitat and the carrying capacity for quail. Raise the carrying capacity by habitat improvements, and within a year the birds will respond; lower it by destroying natural cover and food, and they will quickly die off or move out. This responsiveness to living conditions on the range is due partly to freedom of movement and partly to the rapid annual turnover of birds. More than half of a quail population normally dies and is replaced during the course of a year. If conditions are favorable for replacement and survival, populations will expand quickly; if unfavorable, they will just as quickly decline and disappear.

\section{QUAIL HABITAT}

Characteristics of Quail Habitat.-In considering the essential features of an area, the importance of behavior peculiarities of the birds must be emphasized. Quail take their food in the form of seeds and greens. They probably could obtain the same essential dietary elements from insects and worms, as do many other birds. Their food habits, however, are so ingrained that in captivity quail have been known to starve, even when a bountiful food suppy was offered in an unaccustomed form. The same dependency on habit is seen in relation to brushy cover. Whereas other species with similar needs but different habits, such as the pheasant, get along without such cover, quail simply will not settle or remain on land that lacks it.

The carrying capacity of a tract for quail is determined by the presence and

"Italic numbers in parentheses refer to "Literature Cited" at the end of this bulletin. As will be noted, some of the references are not specifically referred to in the text but are included as reading sources on upland game-bird management. Two later papers on quail projects are:

Glading, Ben, R. W. Enderlin, and H. A. Hjersman.

The Kettleman Hills quail project. California Fish and Game 31:139-56. 1945.

Glading, Ben, David M. Selleck, and Fred T. Ross.

Valley quail under private management at the Dune Lakes Club. California Fish and Game 31:167-83. 1945. 
distribution of food, water, and cover in acceptable forms. Moving about mostly on foot, quail require a broken terrain with a close intermixture of open feeding areas and protective brushy cover. Any farming operations that create broad expanses of single vegetation types are not favorable to quail, even when such areas consist of valuable food or cover plants. A clean-cultivated vineyard, for example, has the necessary brushy element, but lacks food; a large grain field contains much good quail food, but lacks brushy cover. Such large

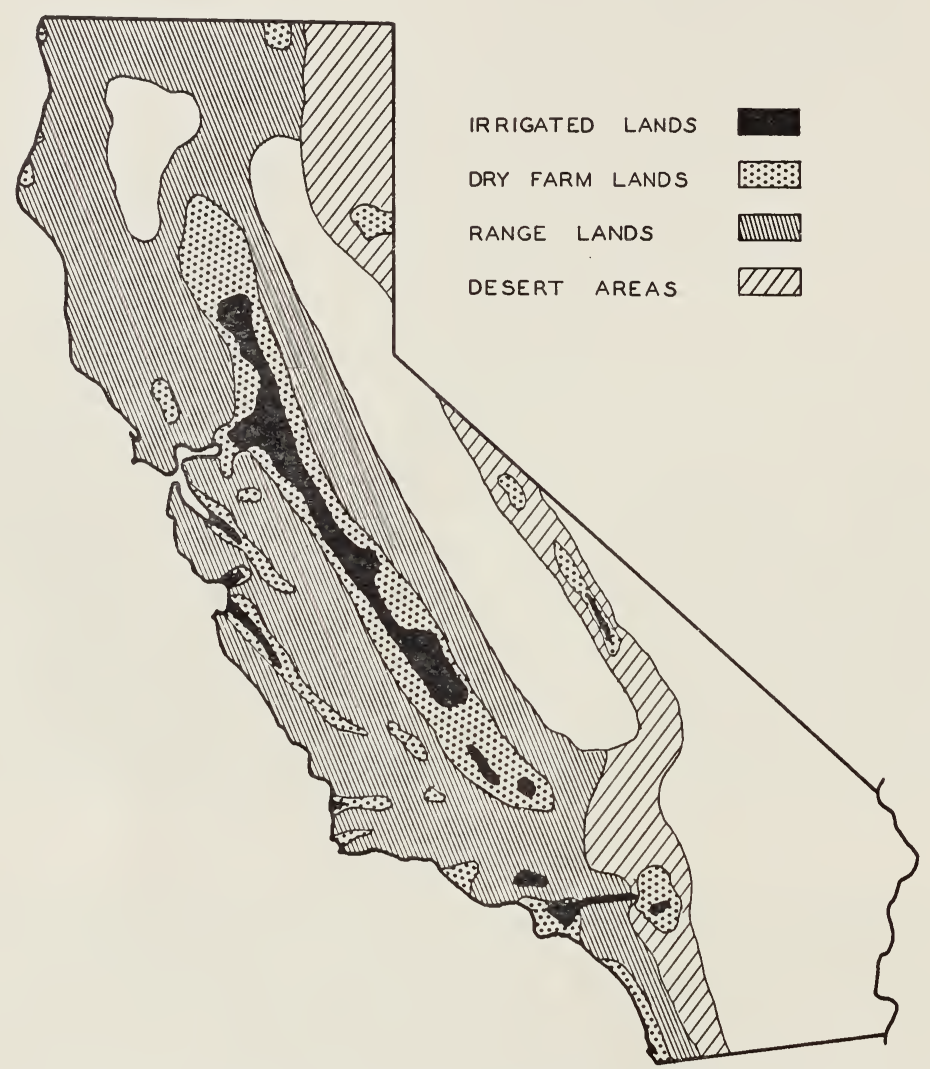

Fig. 1. - The areas in California occupied by valley quail. The four major habitat types are indicated by the different shading.

areas of any single cover or food plant are of little or no use to quail except along the edges. Mixed vegetation with small clumps of trees and shrubs scattered among open feeding areas, as on many foothill range lands, provides a maximum of "edge," and is ideal for quail when water also is available.

The essence of habitat management for quail is the creation of the best possible mingling of feeding areas, protective cover, and watering sites. The highest development of land for quail is attempted only in those rare instances where an area is used solely for quail production. On most lands, the objective of quail management is to create the best possible environment under the limitations imposed by essential land use operations. To achieve this purpose requires a thorough understanding of the birds' habits, requirements, and enemies ; in short, the ability to see the land through the eyes of the quail. 
The essential elements of valley quail habitat are as follows :

1. Food: The birds require an adequate and dependable supply of acceptable seeds in summer, fall, and early winter, and of greens in later winter and spring. (See pages 25-33.)

2. Water : Except under certain unusual circumstances, quail drink at least once a day during the hot summer and fall months. Watering places should be accessible on all parts of the range, and regard must be given to the limited mobility and special cover requirements of newly hatched broods. (See pages 34-38.)

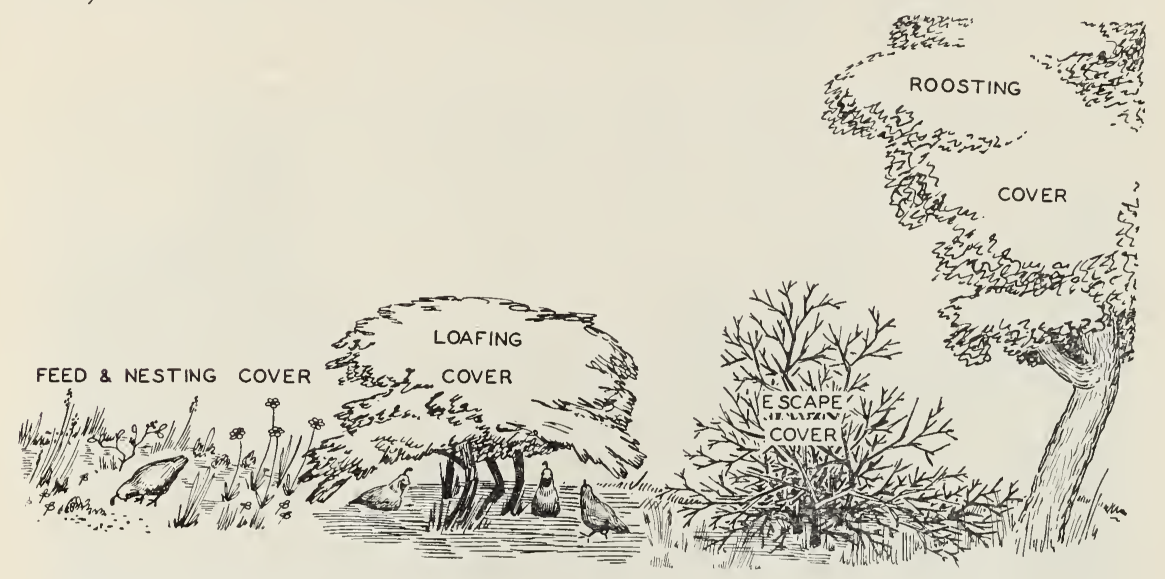

Fig. 2.-The four types of cover for valley quail. In some areas the loafing and escape cover are essentially the same.

3. Cover: The needs of quail for cover or shelter may be listed under five types:

a. Loafing cover : Between feeding periods, quail spend most of their time dozing and preening in secluded spots protected from the sun of summer, the winds and rain of winter, and the eyes of predators. Loafing cover should be close to the feeding areas and should be low. It should be dense enough to provide concealment, yet open enough to permit considerable freedom of movement by the birds and good visibility from within. Dense stands of brush that afford hidden avenues of approach for terrestrial enemies are unsuitable.

b. Escape cover: In their foraging excursions, quail seldom wander more than 50 feet from brushy cover into which they can escape if surprised by an enemy. Cover suitable for loafing is usually good escape cover; but dense, low shrubs, trees, trailing vines, weed patches, piles of debris, and even rock piles are used.

c. Feeding cover : Quail like to feed in clearings or in sparse vegetation that afford them an open view of the sky. They avoid dense thickets of brush or patches of standing grass except where the edges adjoin clearings. When feeding, they will not remain long in a single spot; they like to keep on the move, and feeding grounds should therefore be extensively distributed. 
d. Roosting cover : In most parts of California, valley quail roost at night in densely foliaged trees or in shrubs 5 to 30 feet tall. One good roosting site is normally enough for a covey inhabiting a 30- to 40-acre covey range, but where populations are large and the ranges overlap, numerous sites are needed.

e. Nesting cover : Quail nest on the ground in almost any type of cover that affords a little shade and concealment. The available supply of such cover is usually ample at the beginning of the nesting season. The chief limitation is imposed by farming operations and overgrazing that destroy ground cover after nesting has started.

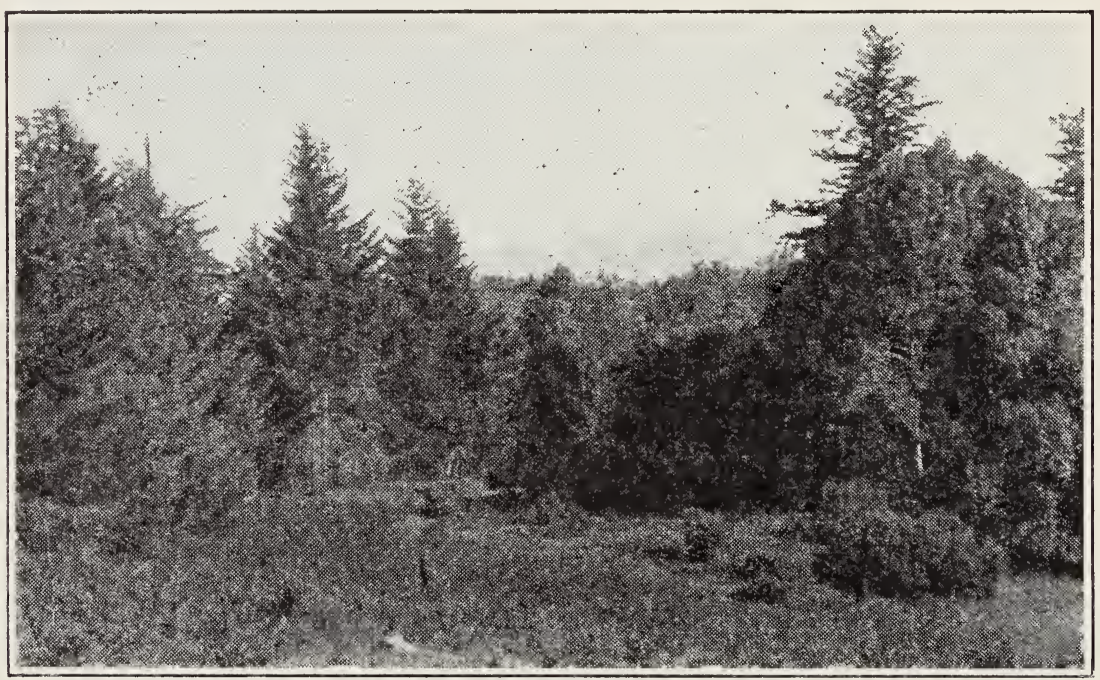

Fig. 3.-Coast Range. Roosting cover: tan-oak and Douglas-fir in background. Escape and loafing cover: shrubs at right. Food: in the clearing at front. (Near Petrolia, Humboldt County ; photograph by T. I. Storer.)

4. Other factors: Quail, like other seed-eating birds, require grit, either fine gravel or other hard particles. Grit is held in the gizzard and aids in "milling" the hard-coated seeds. Certain mineral requirements of nutrition are also thought to be provided by the eroding of grit particles in the gizzard.

Quail like dust baths and use available dusting places frequently. Dusting helps to keep the plumage in good condition and is thought to afford relief from external parasites.

In any management program, all essential features of the habitat must be considered; each is a link in a vital chain. The strength of the chain is determined by the weakest link. The aim of game management is to detect these weak links and to correct them.

Quail Habitats of California.-Valley quail are to be found in nearly all parts of California below the winter snow line, except the eastern half of the Mojave and Colorado deserts (fig. 1). In this wide geographical range they occupy many varied types of habitat (figs. 3-7), each of which involves its own distinct problems. Table 1 roughly classifies habitats of valley quail, giving 
Increasing Valley Quail in California

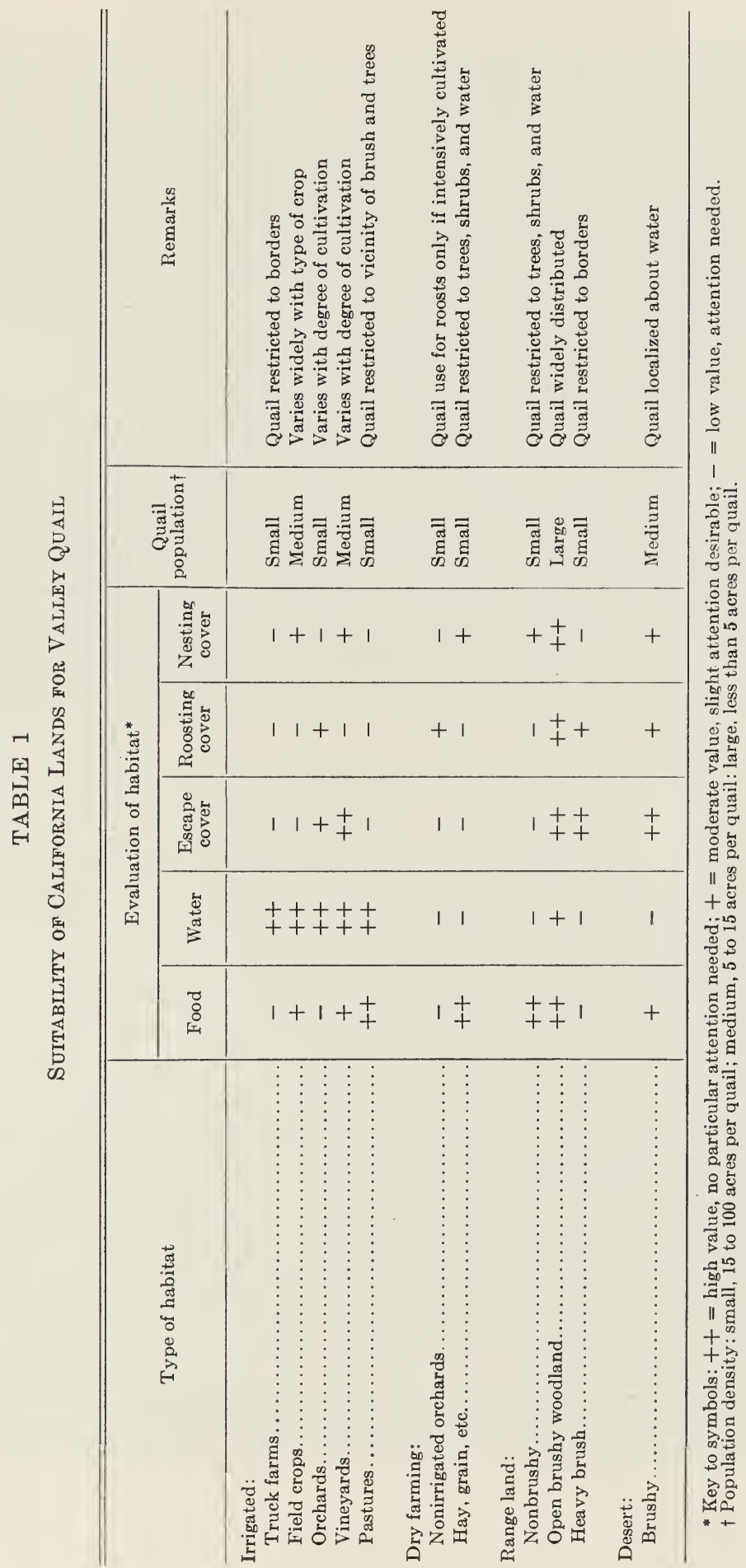




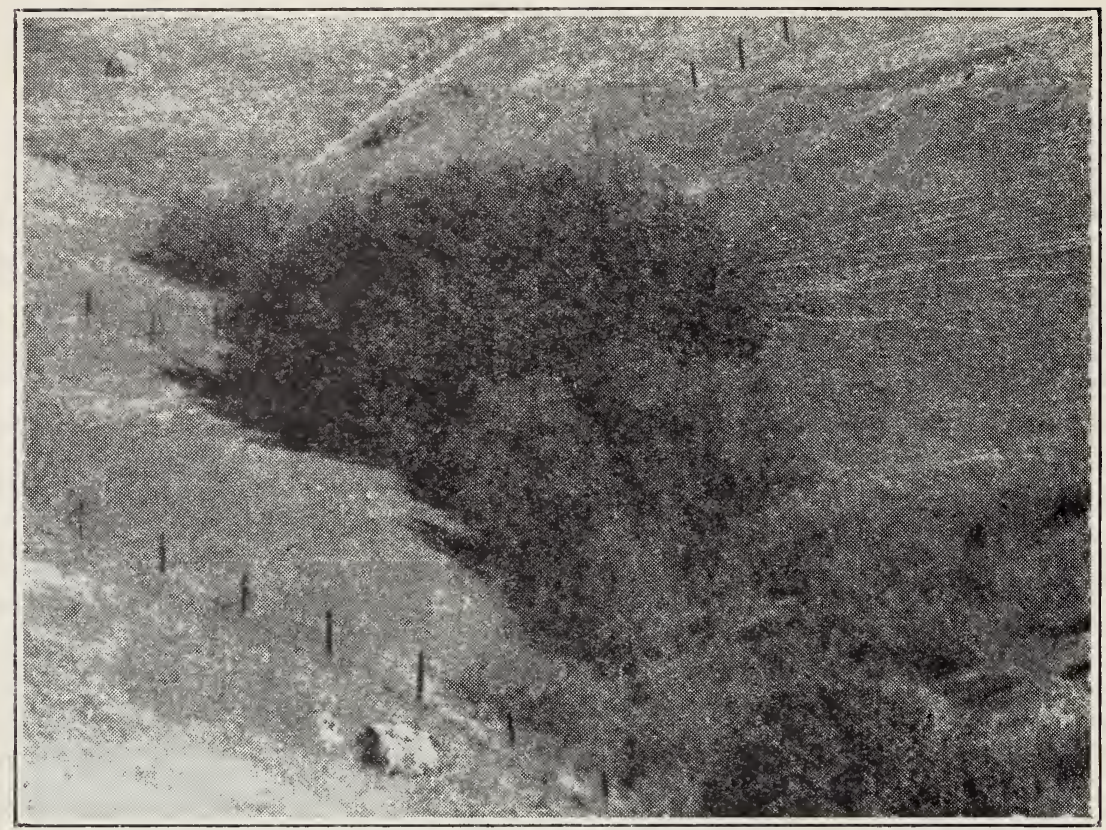

Fig. 4.- Inner Coast Range. Roosting cover: live oak in canyon bottom. Escape and loafing cover: poison oak in right foreground. Food in weed patches on grassy hills beyond. (South side of Mount Diablo, Contra Costa County.)

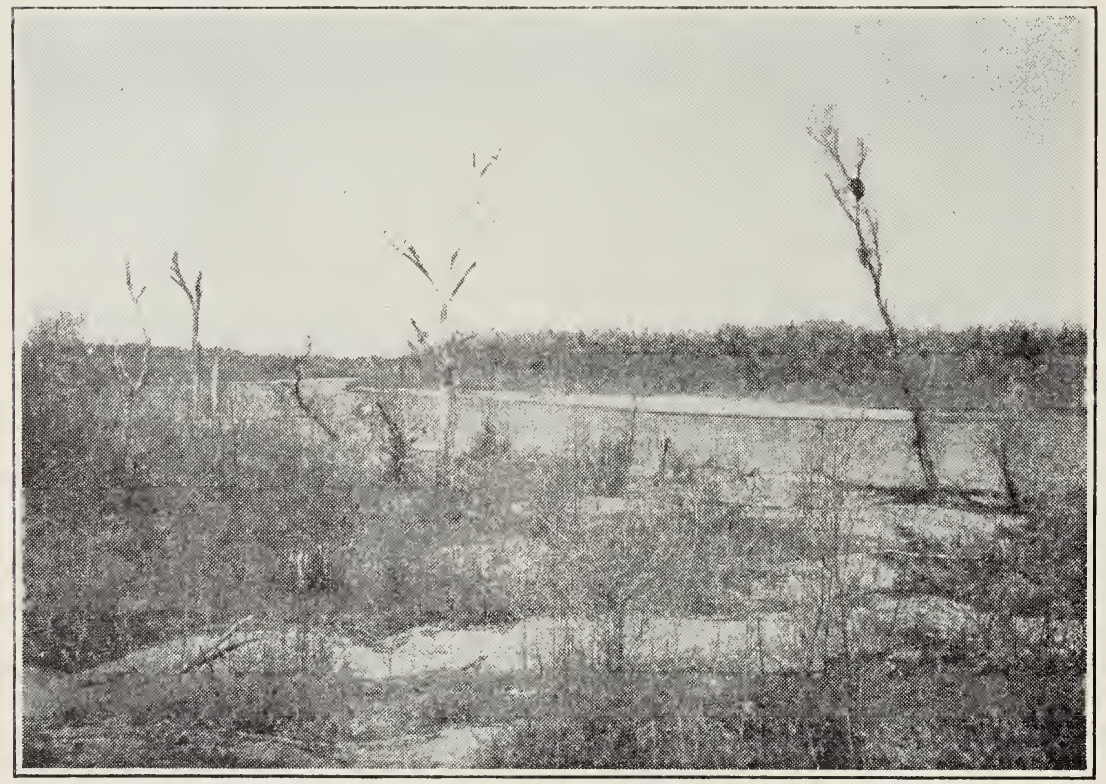

Fig. 5.-Valley river bottom. Roosting cover: willow thickets and mistletoe clumps in the trees along the river. Escape and loafing cover: driftwood and vine tangles under the trees. Food: in neighboring fields and open areas. (Near Marysville, Yuba County; photograph by T. I. Storer.) 


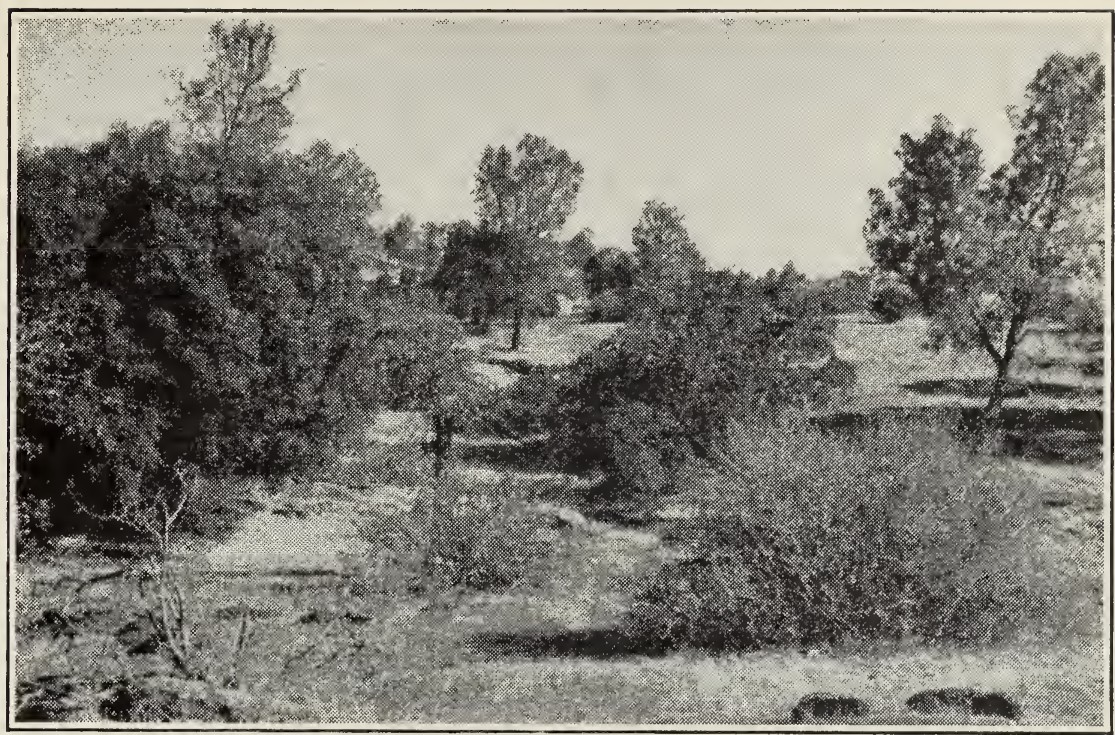

Fig. 6.-Foothills of the Sierra Nevada. Roosting cover: live oak at left. Loafing cover: shrubs in foreground. Escape cover: brush and seattered rock piles. Food: in open areas. (San Joaquin Experimental Range, Madera County; photograph by T. I. Storer.)

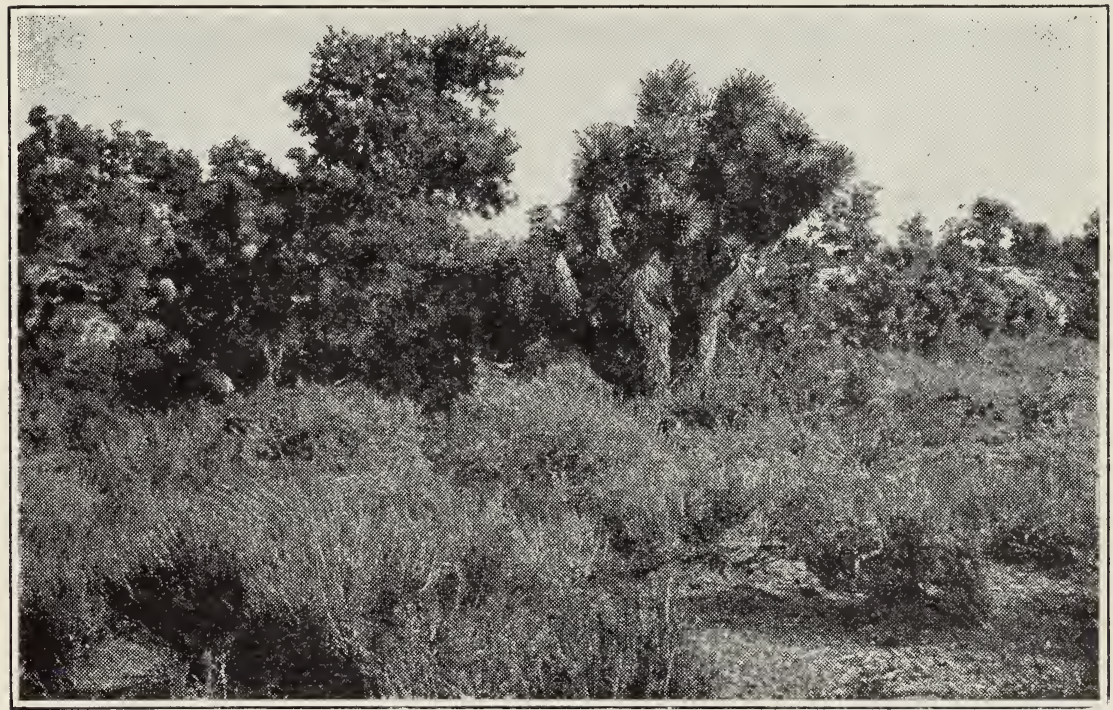

Fig. 7.- Southern California desert area. Roosting cover: piñon pines and junipers. Escape and loafing cover: sagebrush (Artemisia). Food: small annual plants in spaces between plants of sagebrush. (Cactus Flat, San Bernardino County; photograph by T. I. Storer.) 
comments on the populations, habitat deficiencies, and appropriate management procedures for each.

Irrigated truck and field-crop lands are generally deficient in roosting cover, escape cover, and loafing cover, and often in food (fig. 2). It is not always feasible to attempt quail management on such lands; but, where possible, a few simple improvements in field corners and along fences can do much to encourage quail. The birds that persist along sloughs, creek banks, and submarginal borders in such agricultural areas will quickly move out into new territory as it is made usable to them by improvement of food and cover. Orchards and vineyards often provide ample cover, yet, when clean-cultivated, are deficient in food. Where the operator can safely leave small stands of weedy cover along the vineyard or orchard borders, there will commonly be a local increase in quail.

Dry-farming areas in California produce an abundance of quail foods, but as a rule are seriously deficient in protective cover and in drinking water. Where these latter items are introduced around farm houses and along field borders, the quail respond by rapid increase. Further planned developments could make excellent quail range of vast acreages now barren of these birds (figs. 811.) The necessary improvements would involve little or no sacrifice and sometimes would be of benefit to the farming program.

The extensive range lands of the coastal and interior foothills contain some of the best quail country remaining in California. The open oak forests on many of these lands generally have excellent interspersion of food and cover. Water is the chief limiting factor, as indicated by the migrations which quail make every summer from dry hillsides to the vicinity of water holes. Providing new watering sites has been highly effective as a management method on such lands. The food supply is sometimes deficient both on undergrazed areas and on those heavily grazed by sheep-situations that often can be improved by regulating the grazing according to the best interests of the land and the livestock. Brush clearing on chaparral lands with too dense a cover will be of benefit to both quail and livestock. Conversely, brush planting will foster quail on certain treeless and brushless range lands.

The desert areas of southern California support good quail populations where water is available throughout the dry season. Food and cover conditions are usually satisfactory. Being largely under public ownership, desert lands are primarily the concern of government agencies. The California Division of Fish and Game, aided by federal funds, has embarked on an extensive program of quail management on the southern California deserts.

Detecting Habitat Deficiencies.-For a clear understanding of the habitat deficiencies on any particular management area, a detailed survey is needed, recording on a large-scale map the existing food, cover, and water facilities. The first step is to prepare a base map showing field boundaries, fence lines, and prominent landmarks. For this purpose the topographic sheets published by the United States Geological Survey, on a scale of 1 to 4 inches per mile are very useful. Pertinent features of the area should be transferred from these sheets to a large outline map having a scale of about 8 inches to the mile. Corrections should be made for recent changes in roads and any local improvements not shown on older map sheets. The locations of property lines can be 
obtained from the county assessor's office and drawn on the large-scale map. Further details often may be added through personal knowledge of the area or by careful study of air-photo maps if available. The large-scale land-use maps of the Agricultural Adjustment Administration, which may be purchased for certain areas from county AAA offices or the United States Soil Conservation Service, are useful, especially in hilly country where fields and landmarks are irregularly spaced.

After a satisfactory base map has been obtained or prepared the important features of the habitat for quail should be plotted; these include the existing roosting cover, brushy cover, water sources, and, where possible, feeding areas. Information for this cover charting may sometimes be obtained by studying good air-photo maps or type maps of vegetation such as have been recently published for a few areas in the state by the California Forest and Range Experiment Station at Berkeley ; but most of the details must be supplied by field mapping. A plane table is helpful for cover mapping in the field, but an adequate picture of the spacing and distribution of habitat features can usually be made without special equipment by a careful observer familiar with the tract under survey. A compass is often needed in hilly country, and the mapper should know accurately the length of his normal stride. Each significant habitat feature of the area should be located on the map with an appropriate symbol. A convenient system of map symbols, more or less standardized for habitat-survey maps by wildlife managers, is used in this paper (figs. 8-11). Cover and water features are usually easy to map. Food sources, because of their wide distribution and seasonal nature, are difficult to locate with precision, and should not be shown.

Duplicate base maps with a few outstanding features of the cover should be made to record the location of quail coveys during each winter season. On most areas, each covey is restricted closely and tends to stay on a definite range of 30 to 40 acres throughout the winter. On small tracts that are examined regularly by an observer during routine farm operations, the plotting on a map of each observation on quail will provide a fairly accurate record of covey distribution. At the end of the season, the map can be marked with figures showing the approximate size of each covey, based on many observations. On areas less intensively farmed and on large tracts of foothill range where the distribution is more continuous, casual population surveys are not satisfactory and specially organized census drives are needed. (See the section entitled "Harvesting the Quail Crop.")

The details of quail distribution as shown on a population survey map should be studied carefully in relation to cover, food, and water distribution as shown on the corresponding habitat survey map. The manager who makes full use of such maps can clearly picture the types of land naturally favored by quail. Such first-hand knowledge is invaluable in planning a program.

Laying the Management Plans.-The objective of a habitat-management program is to make as much as possible of the total acreage suitable for supporting a maximum number of quail. Success depends, first, on a proper evaluation of the habitat and its deficiencies ; and second, on a wise decision about the corrective measures needed. These are problems for individual judgment; each local manager must solve them on the basis of his experience, keenness, 
and knowledge of tested practices. Careful planning at the outset will prevent much waste of time, effort, and money.

The thoughtful manager who knows all the essential requirements of habitat can, with the help of cover maps and population maps, plan with considerable
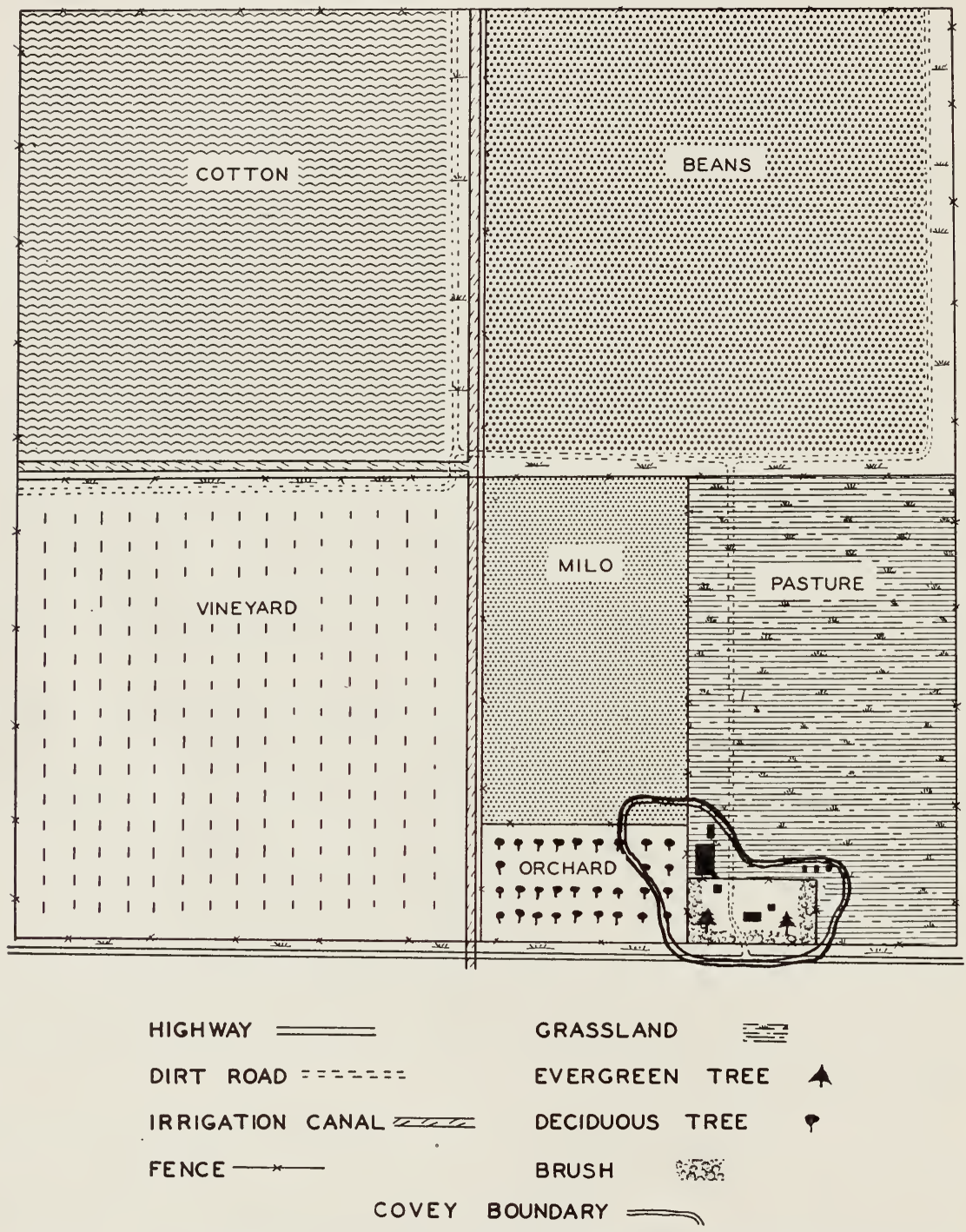

Fig. 8.-Plan of an irrigated farm before conditions for valley quail have been improved. Range of one quail covey outlined about the farm buildings. The same farm improved is shown in figure 9.

accuracy just where and how to establish new coveys by making improvements on land formerly uninhabitable for quail. Each vacant area on the population map should be studied carefully, and an attempt made to understand the reasons for absence of quail. Means of correcting the one or more key deficiencies 
of each blank area should then be considered with full regard to the special habits and restricted movements of the birds. Prospective improvements should be plotted on a cover map, using colored marks or different symbols to distinguish proposed developments from existing features (figs. 8-11).

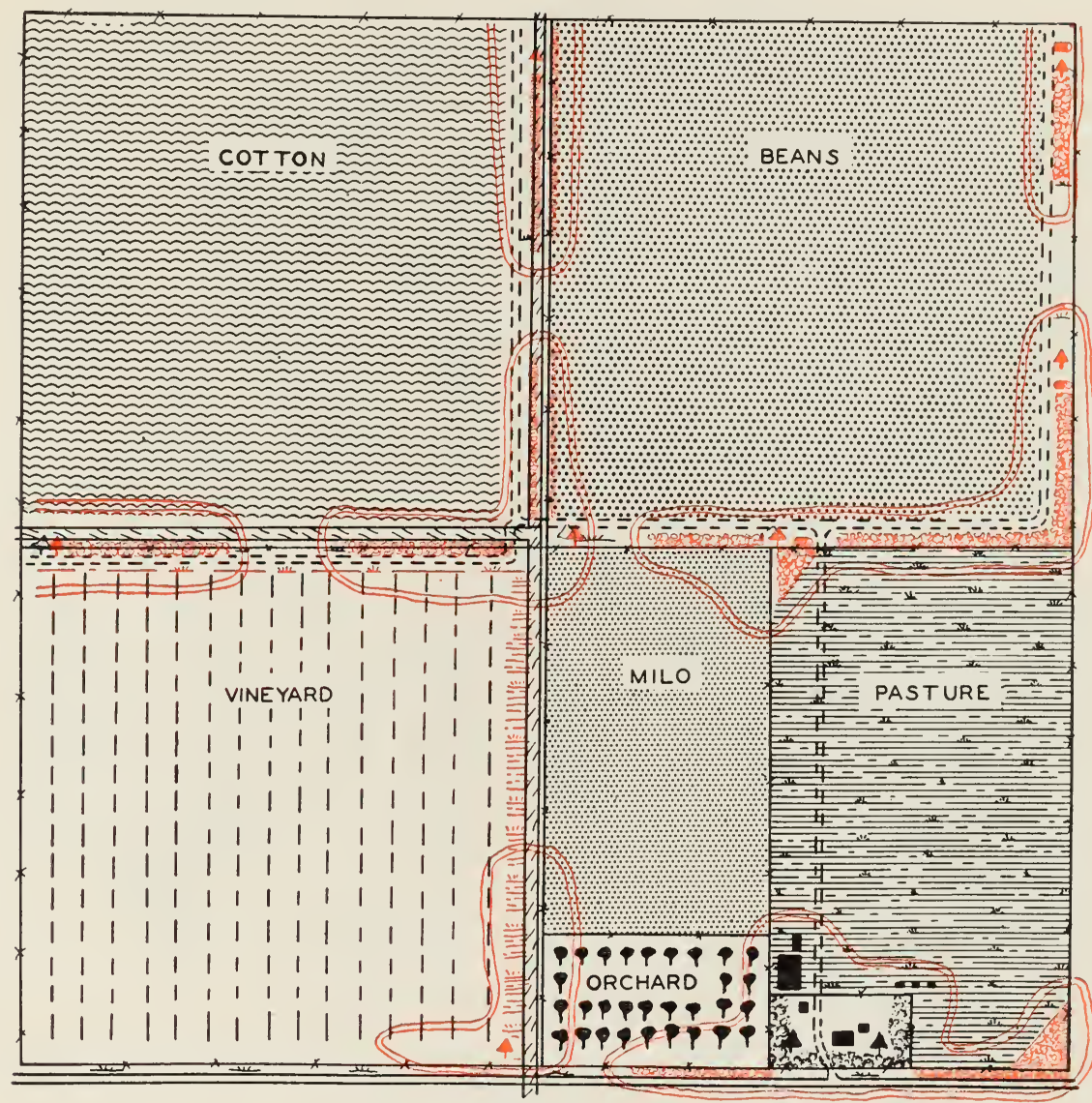

VACUUM TYPE QUAIL WATER TROUGH -

Fig. 9.-The same farm as shown in figure 8, after conditions have been improved for quail. Trees and shrubs for roosting and escape cover have been planted along margins of roads and fields; these, together with new fences and covey boundaries, are shown in red. Other legend as in figure 8.

This working-plan map should be at hand for frequent reference during the habitat-improvement program.

\section{IMPROVING COVER CONDITIONS}

The cover-improvement program should attempt to create an adequate amount and a proper balance of each of the cover types required by quail. Some areas need more cover of all types; others require selective changes in existing cover, to encourage types of brush providing both food and cover and at the same time to discourage unsuitable species. 
Encouraging Natural Vegetation.-Vegetation suitable for roosting, loafing, escape, and nesting cover may be increased either by reducing or removing the factors that prevent its natural growth, or by actual planting and culture. The vegetation on heavily grazed lands is often held back by the feeding activ-

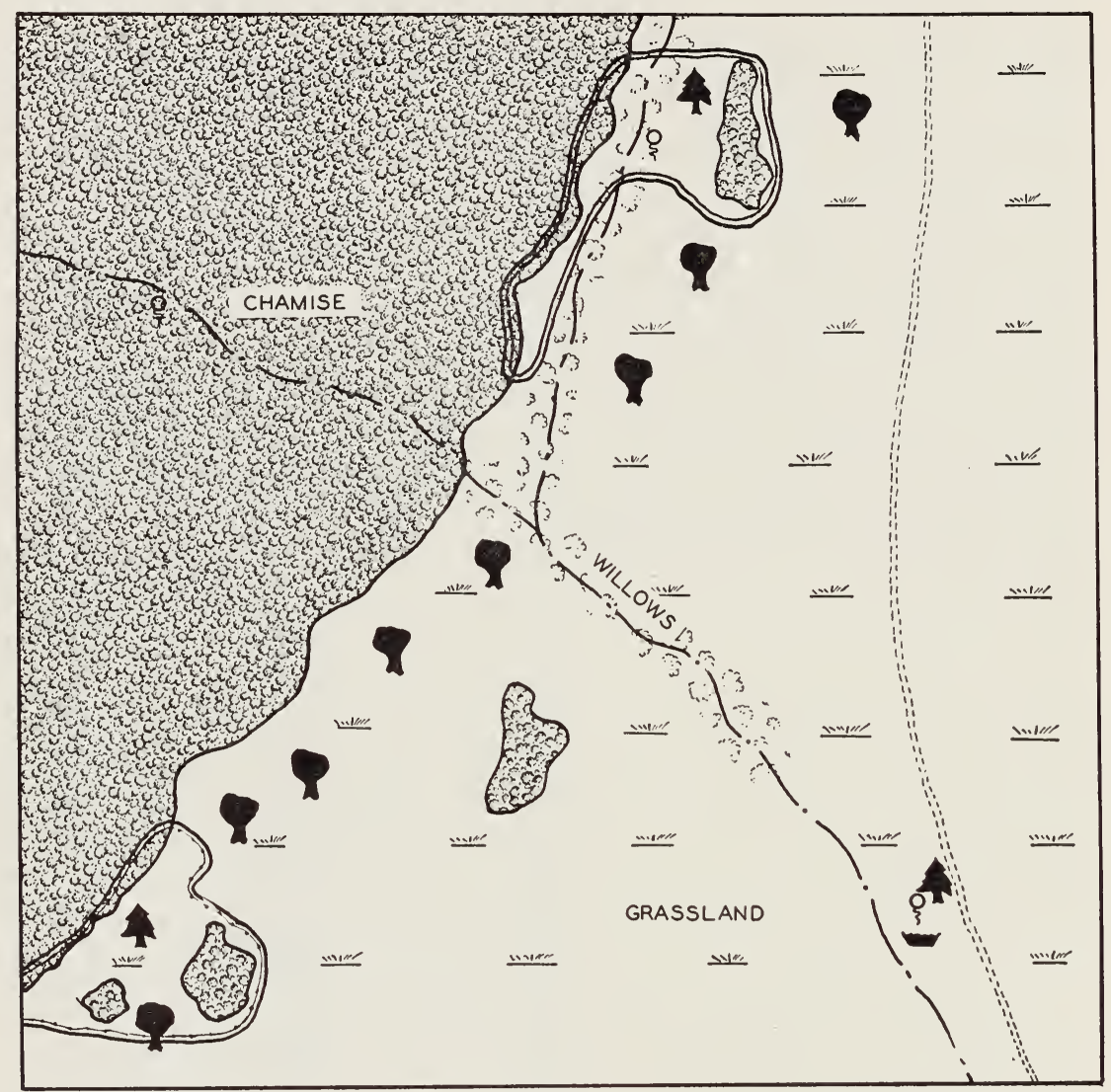

SPRING 9

CATTLE TROUGH

INTERMIT TENT STREAM - - -

Fig. 10.-Plan of a section of foothill range land before conditions for valley quail have been improved. Ranges outlined for two coveys present. Covey area suitable for winter occupancy is shown by a broken inside line. Other legend same as figure 8.

ities of livestock. The fencing of small plots in swales, around clumps of heavily browsed shrubs, near water troughs, or in pasture corners will usually result in rapid natural regeneration of good escape cover and loafing cover. On range lands where the ground about a water hole has been trampled to dust or mud, a stockproof, fenced plot including at least a part of the water hole should be built. Such plots, protected from grazing and trampling, will soon develop a growth of weeds and grasses useful as protective cover for adult quail or young broods, which would hesitate to use an exposed water hole. 


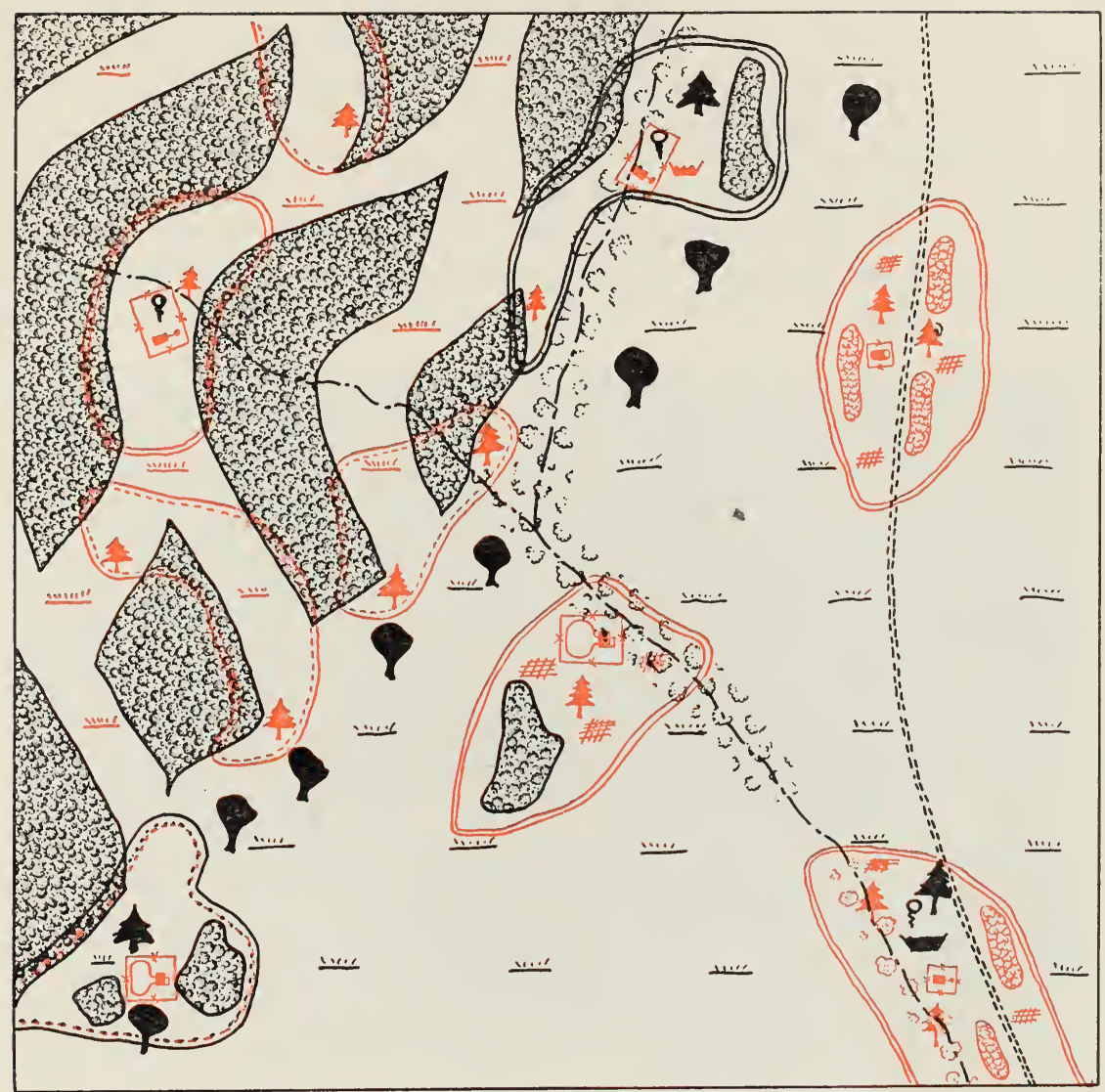

BRUSH PILE SHELTER

TYPES OF QUAIL WATER TROUGHS:

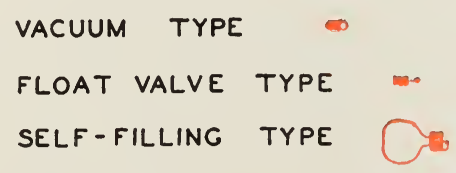

Fig. 11.-The same section of foothill range as in figure 10, after conditions have been improved for quail. Openings have been made in the chamise (chaparral), additional roosting trees and escape or loafing cover (brush) have been planted on the flat portions, and watering devices have been placed at several points in the area. Ranges of additional quail coveys possible with the improvements are outlined. All new features shown in red. Other legend same as in figures 8 and 10.

Grassy nesting cover should be protected as much as possible from heavy grazing by sheep until after the nesting season for quail ends in July. A plan of pasture rotation that leaves small valleys and swales for early summer use by quail and later use by livestock is good range management as well as good quail management. 
Planting Quail Cover.-In many places planting is desirable or necessary to establish permanent cover patches of proper types. Any such program involves considerable time and labor and should be carefully planned in accordance with the requirements of the birds and the qualities of the land. Each cover development must be considered in its relation to other existing or proposed food, cover, and water facilities; small, isolated patches, regardless of their quality, are worthless to quail. Clumps of plants for escape and loafing cover should be 10 to 20 feet in diameter and not more than 200 feet from other escape cover. Continuous or interrupted hedges of good dense shrubs are eco-

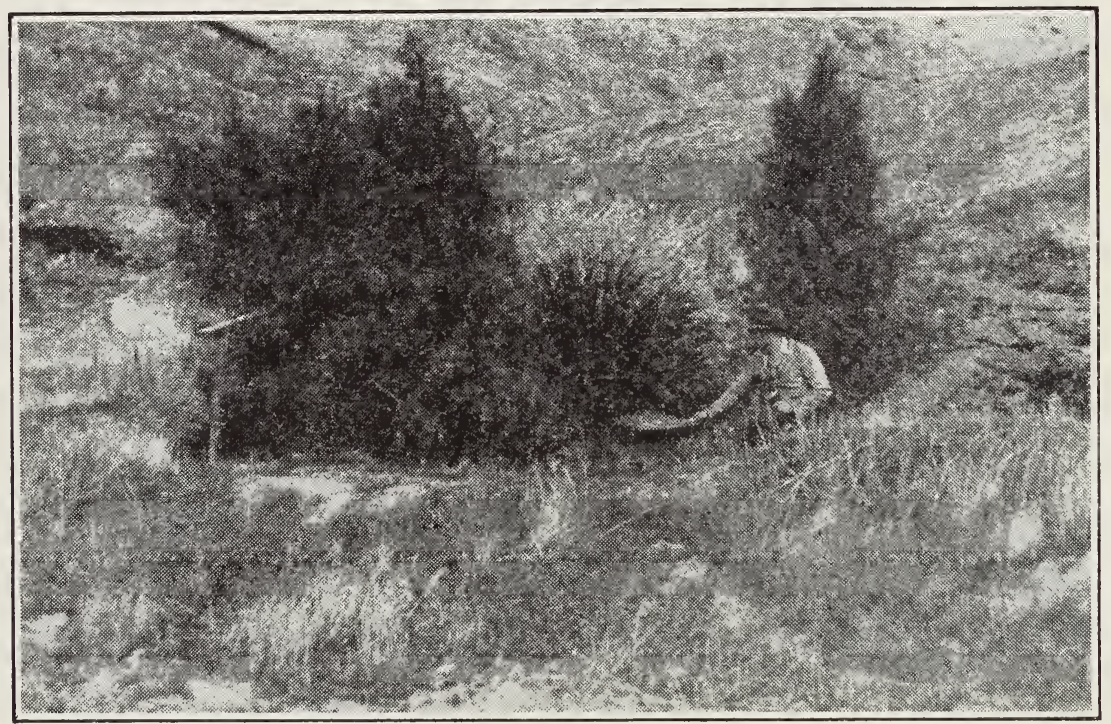

Fig. 12.-Planted cover. Roosting cover: these one-year-old tamarisk trees will soon grow large enough to provide a roosting place. Loafing cover: under the edge of the (planted) pampas grass. Escape cover and food: naturally abundant on rough lands nearby. (Kettleman Hills, Fresno County.)

nomical and effective for cover planting and particularly useful as interconnecting "bridges" or routes for quail between larger patches of cover. A loose network of hedges and brush patches will make large areas, previously uninhabitable, available for occupancy by quail. Roosting cover should be available at quarter-mile intervals over quail range. Although one good roosting tree is enough at a site, it is well to set out a group of young trees to insure against loss or poor growth (fig. 12).

The locations of plantings on agricultural land must be determined largely by the primary land use. Some cover improvements for quail can be fitted into farm programs with little interference and often with positive benefit. On high-quality truck and crop land, cover developments will usually be restricted to submarginal borders or the vicinity of buildings. Odd corners more or less inaccessible to farm machinery can sometimes be planted with brushy cover. Many farmers consider that attractive plantings in such places improve the general appearance of a farm. In hilly country, certain shrubs valuable as quail cover also have important soil-binding properties and are 
recommended by the United States Soil Conservation Service for planting along gullies and washes. Where windbreaks are desirable along field borders, hedges of osage-orange, cypress, or tamarisk will protect the fields and also provide adequate escape, loafing, and sometimes roosting cover for quail. Some of the best kinds of roosting trees are excellent for shade around farm buildings and on pasture lands; broad-leaved evergreens such as olives, citrus, and live oaks are ideal. When planting brushy cover on range lands it is possible and often desirable to use species such as the saltbushes that will ultimately benefit cattle as well as quail. After a few years of fenced protection, saltbushes will develop enough woody growth so that they can be used by cattle, yet not be browsed out.

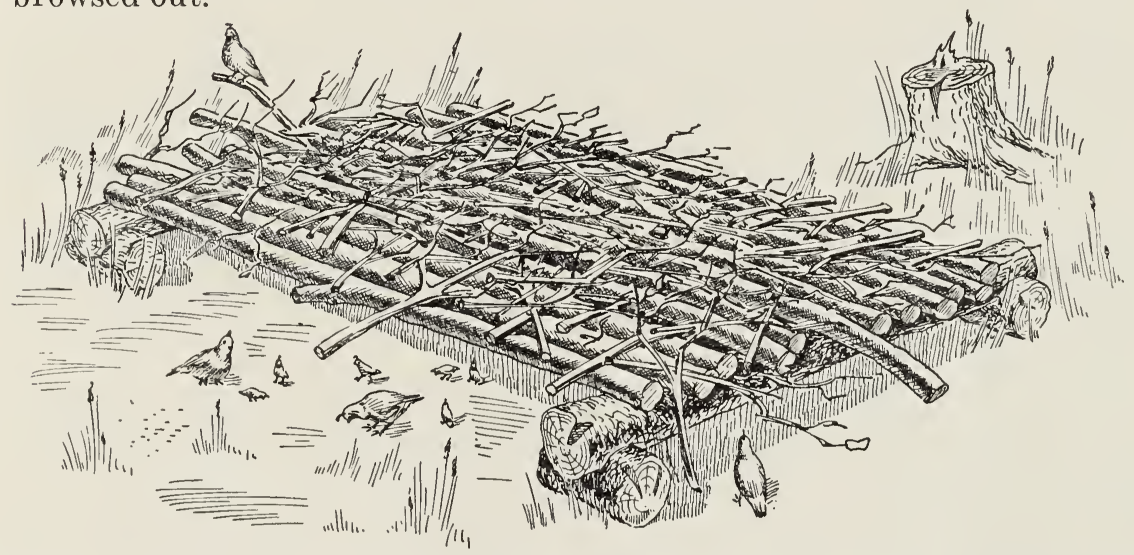

Fig. 13.- Shelter of brush and small logs as constructed for bobwhite quail by the Texas Game, Fish, and Oyster Commission. Similar shelters will provide loafing cover for valley quail in California.

Shrubs and trees suitable for quail cover vary widely in their cultural and climatic requirements $(9,11,22)$. Where there is any doubt about climatic or soil tolerances, it is a good rule to use plants that are native locally. Hints on methods of planting and culturing are given in table $2 .{ }^{7}$ Some species may be established by simply broadcasting seed into roughly scratched patches of ground (21); others must be grown in pots for a year or more and then transplanted to the permanent sites. Many desirable brush species can be started by transplanting freshly cut slips or young plants newly dug from other places.

Most of the plants listed in table 2 are reasonably resistant to drought and need little attention after being set out. All need water at the start, but much of this can be supplied by rain if planting is done early in the rainy season. As a rule, the species that require special care are suitable only near residences or in other places where water is readily available.

Some of the best cover plants, particularly the densely foliaged roosting trees such as citrus, oaks, and juniper, grow very slowly. Often, when establishing such plants, it is well to set out some faster-growing type such as ever-

\footnotetext{
${ }^{7}$ Leaflets dealing with the culture of native California shrubs and trees are published by the Rancho Santa Ana Botanic Garden at Anaheim, California. Many of these deal with species that are excellent as quail cover. Additional advice or help in obtaining planting stock may be had from the local farm advisor or from any nearby district office of the United States Soil Conservation Service.
} 


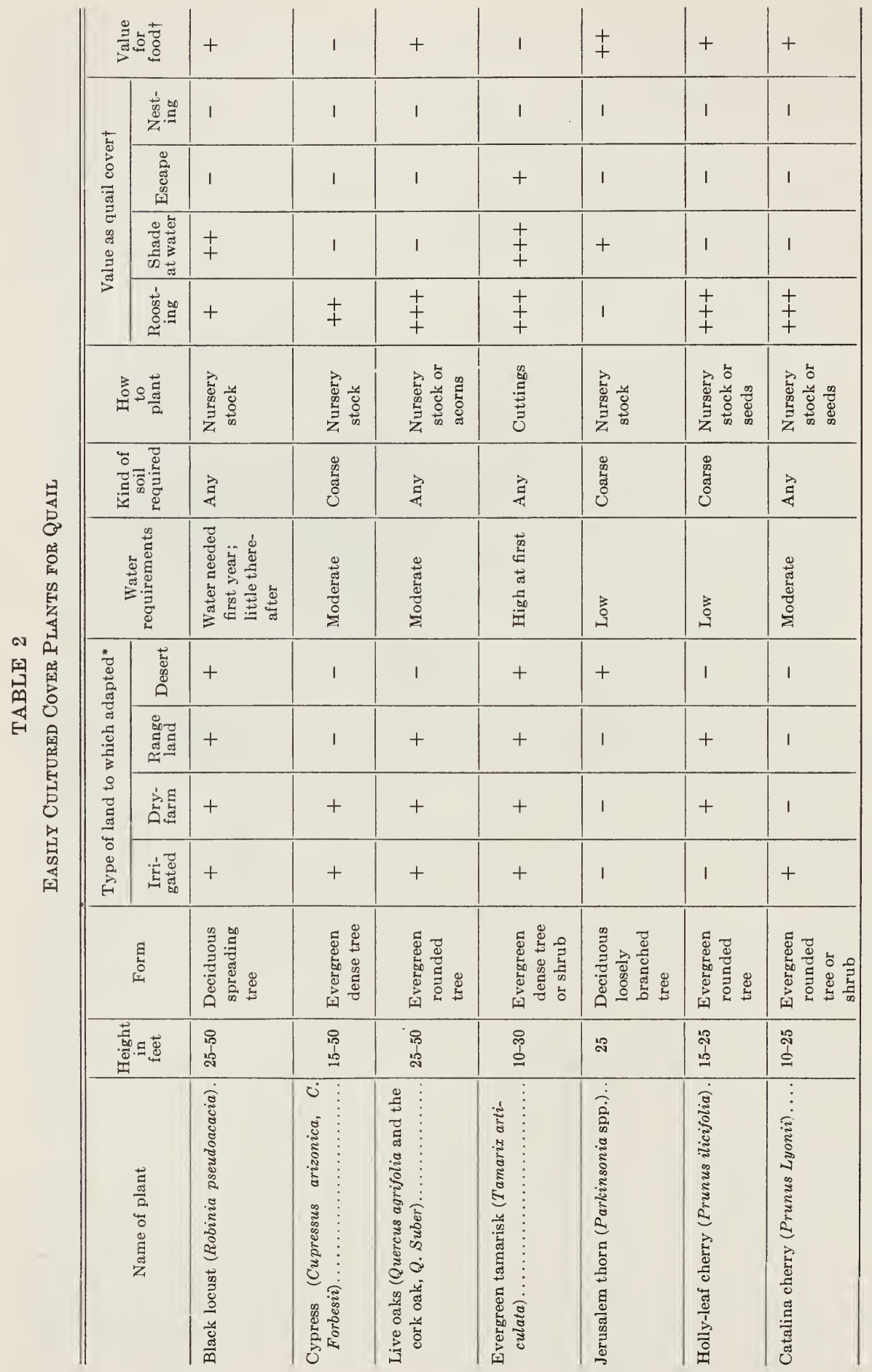


Increasing Valley Quail in California

\begin{tabular}{|c|c|c|c|c|c|c|c|c|c|}
\hline 1 & + & + & + & + & 1 & 1 & + & + & \\
\hline 1 & 1 & 1 & 1 & 1 & 1 & 1 & 1 & 1 & \\
\hline \pm & + & 1 & + & 1 & 1 & + & \pm & + & हك \\
\hline+ & $\stackrel{+}{+}$ & + & + & \pm & 1 & 1 & I & I & " \\
\hline+ & $\begin{array}{l}+ \\
+ \\
+\end{array}$ & I & + & + & $\stackrel{+}{+}$ & $\begin{array}{l}+ \\
+\end{array}$ & + & + & $\Xi$ \\
\hline 莺 & 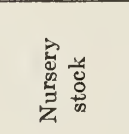 & 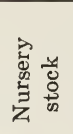 & 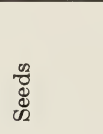 & 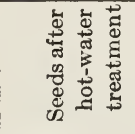 & 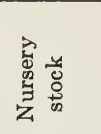 & 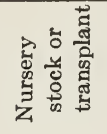 & 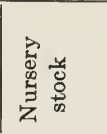 & 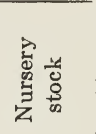 & 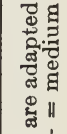 \\
\hline $\overrightarrow{\frac{a}{4}}$ & $\overrightarrow{\mathrm{d}}$ & $\overrightarrow{4}$ & $\vec{\xi}$ & 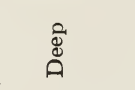 & $\begin{array}{l}\text { Z: } \\
8 \\
0\end{array}$ & $\hat{\mathrm{g}}$ & $\begin{array}{l}0 \\
\text { कू } \\
\tilde{0} \\
0 \\
0\end{array}$ & 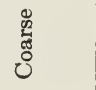 & $\vec{a}$ \\
\hline 战 & 艿 & مِ & 言 & ڤ్ & 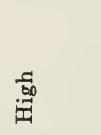 & $\stackrel{\sqrt{00}}{\overrightarrow{4}}$ & 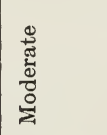 & $\begin{array}{l}\frac{ \pm}{\pi} \\
\frac{\pi}{50} \\
\frac{0}{2}\end{array}$ & 18 \\
\hline+ & + & + & + & + & 1 & 1 & I & 1 & \\
\hline+ & + & + & + & 1 & 1 & 1 & + & + & 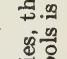 \\
\hline+ & + & 1 & + & 1 & 1 & 1 & 1 & 1 & $=$ \\
\hline+ & + & 1 & I & 1 & + & + & 1 & 1 & $\varepsilon$ \\
\hline 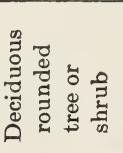 & 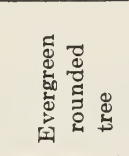 & 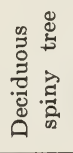 & 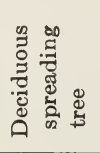 & 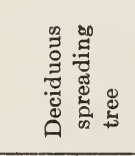 & 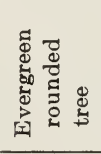 & 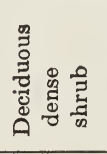 & 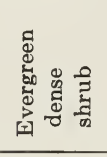 & 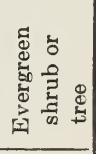 & $\bar{\sigma}$ \\
\hline 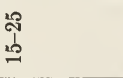 & $\begin{array}{l}\text { : } \\
\text { : } \\
\text { 19. }\end{array}$ & ని & จิ & ฉి & శి & $\begin{array}{l}\text { के } \\
\text { oे }\end{array}$ & $\stackrel{2}{2}$ & $\frac{20}{6}$ & 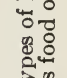 \\
\hline 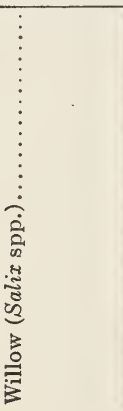 & 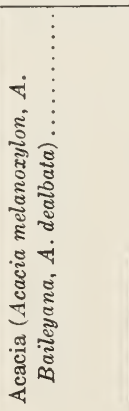 & 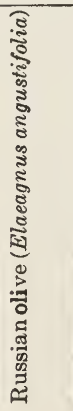 & 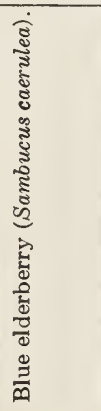 & 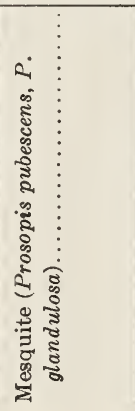 & 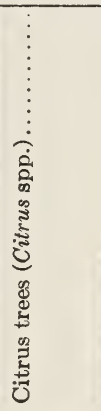 & 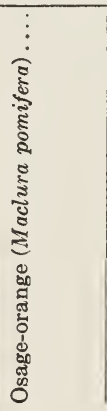 & 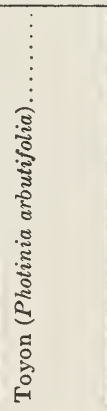 & 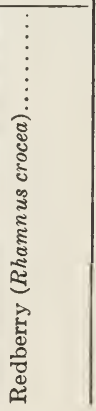 & 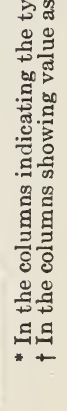 \\
\hline
\end{tabular}




\begin{tabular}{|c|c|c|c|c|c|c|c|c|c|}
\hline 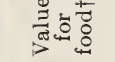 & 1 & 1 & 1 & 1 & + & + & 1 & + & + \\
\hline 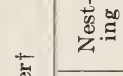 & 1 & + & 1 & 1 & + & 1 & + & + & 1 \\
\hline 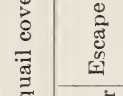 & + & $\begin{array}{l}+ \\
+ \\
+\end{array}$ & + & $\stackrel{+}{+}$ & $\begin{array}{l}+ \\
+ \\
+\end{array}$ & + & + & $\begin{array}{l}+ \\
+ \\
+\end{array}$ & $\begin{array}{l}+ \\
+ \\
+\end{array}$ \\
\hline 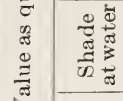 & 1 & 1 & 1 & 1 & 1 & 1 & 1 & + & 1 \\
\hline . & + & 1 & 1 & + & 1 & + & 1 & + & 1 \\
\hline$\stackrel{\overrightarrow{0}}{=}+\frac{\vec{E}}{a}$ & 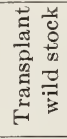 & 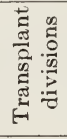 & 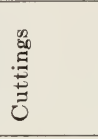 & 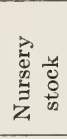 & 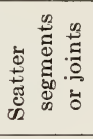 & 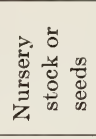 & 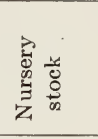 & 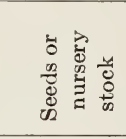 & 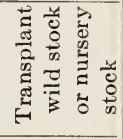 \\
\hline 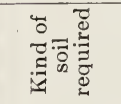 & है & $\begin{array}{l}ت \\
8 \\
0 \\
ن\end{array}$ & $\hat{\xi}$ & 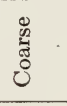 & 育 & $\vec{\xi}$ & 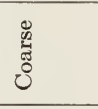 & $\vec{\Xi}$ & $\vec{E}$ \\
\hline 总离 & 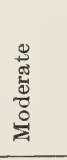 & 娄 & 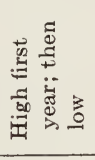 & 3 & 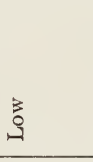 & 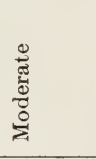 & 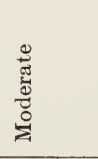 & 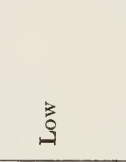 & 㺃 \\
\hline 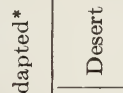 & + & 1 & + & 1 & + & 1 & + & + & 1 \\
\hline 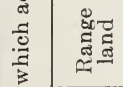 & + & + & + & + & + & + & + & + & + \\
\hline 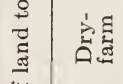 & 1 & + & 1 & + & + & + & 1 & + & 1 \\
\hline 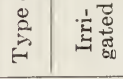 & 1 & + & 1 & 1 & + & + & 1 & 1 & 1 \\
\hline हี & 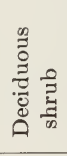 & 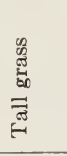 & 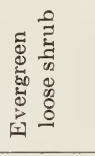 & 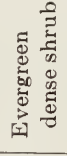 & 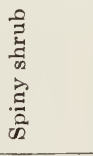 & 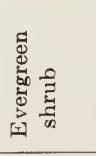 & 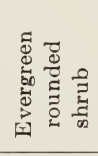 & 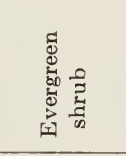 & 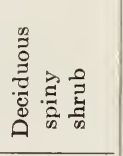 \\
\hline 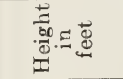 & $\subseteq$ & 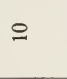 & $\frac{1}{b}$ & $\frac{0}{b}$ & $\frac{0}{1}$ & $\begin{array}{l}\infty \\
b\end{array}$ & 0 & I & 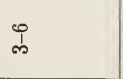 \\
\hline 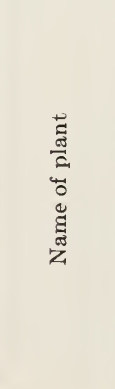 & 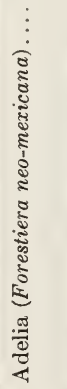 & 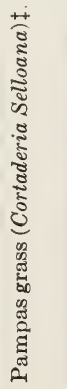 & 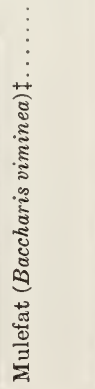 & 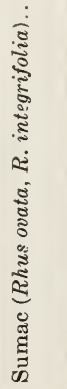 & 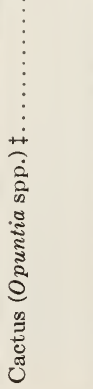 & 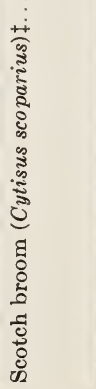 & 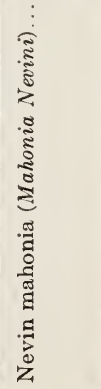 & 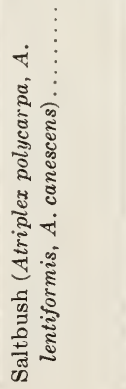 & 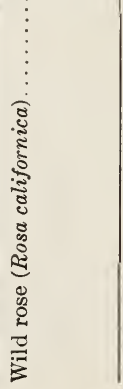 \\
\hline
\end{tabular}




\begin{tabular}{|c|c|c|c|c|c|c|c|c|c|c|}
\hline+ & 1 & + & + & + & + & I & I & + & + & \\
\hline 1 & + & + & + & + & + & + & + & + & + & $\begin{array}{l}0 \% \\
\Xi\end{array}$ \\
\hline$\stackrel{+}{+}$ & + & + & $\begin{array}{l}+ \\
+\end{array}$ & $\begin{array}{l}+ \\
+ \\
+\end{array}$ & + & $\begin{array}{l}+ \\
+ \\
+\end{array}$ & $\begin{array}{l}+ \\
+ \\
+\end{array}$ & + & + & 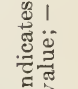 \\
\hline 1 & 1 & 1 & 1 & 1 & 1 & 1 & 1 & 1 & 1 & $\frac{d}{62} \frac{9}{6}$ \\
\hline 1 & 1 & 1 & 1 & 1 & 1 & 1 & 1 & 1 & 1 & $\Xi \frac{\pi}{\sigma}$ \\
\hline 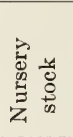 & $\begin{array}{l}\frac{n}{g} \\
\Phi \\
\text { Dू }\end{array}$ & 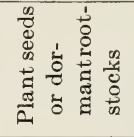 & 总 & 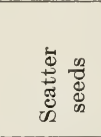 & $\begin{array}{l}\frac{n}{g} \\
\mathbb{d} \\
\text { D. }\end{array}$ & 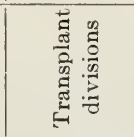 & 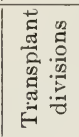 & 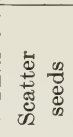 & 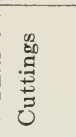 & 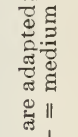 \\
\hline 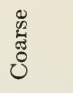 & 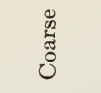 & 宅 & 安 & $\vec{a}$ & 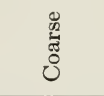 & 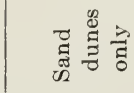 & 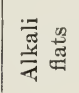 & 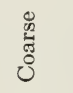 & $\vec{a}$ & 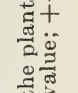 \\
\hline 芯 & 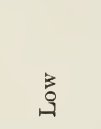 & 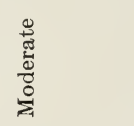 & $\underset{\mathbb{E}}{\tilde{E}}$ & בְ & 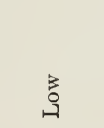 & مُ & 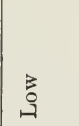 & 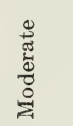 & 爯 & 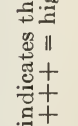 \\
\hline 1 & + & 1 & + & + & + & + & + & 1 & 1 & \\
\hline+ & + & + & + & + & + & + & + & + & 1 & \\
\hline 1 & 1 & + & + & + & 1 & 1 & + & 1 & 1 & $\Rightarrow 9$ \\
\hline 1 & 1 & 1 & + & 1 & 1 & 1 & 1 & 1 & + & $=$ \\
\hline 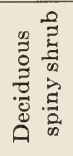 & 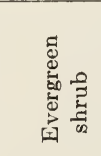 & 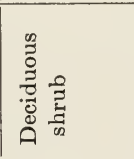 & 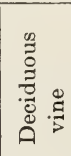 & 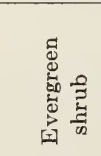 & 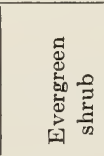 & 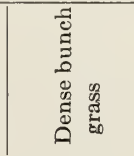 & 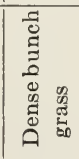 & 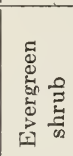 & 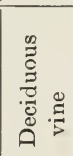 & 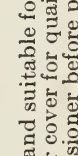 \\
\hline $\begin{array}{l}0 \\
\vdots\end{array}$ & i & $\begin{array}{l}0 \\
0 \\
\infty\end{array}$ & $\stackrel{p}{a}$ & I & $\infty$ & $\stackrel{p}{q}$ & N & - & $\vdots$ & 0 \\
\hline 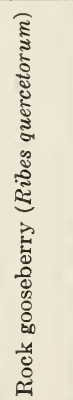 & 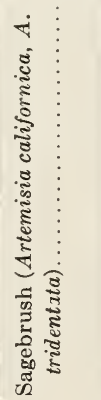 & 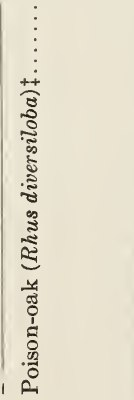 & 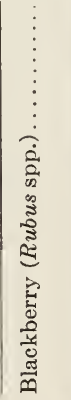 & 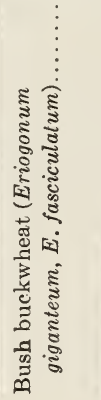 & 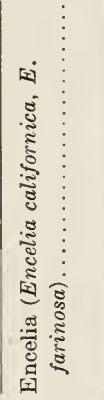 & 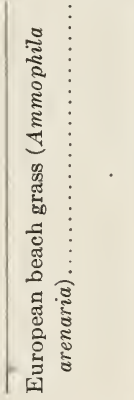 & 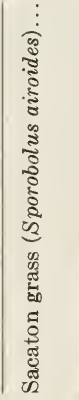 & 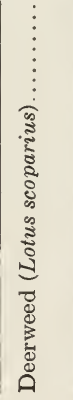 & 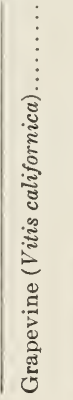 & 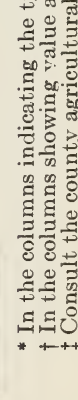 \\
\hline
\end{tabular}


green tamarisk at the same time; then, as the slow-growing trees attain usable size, the less desirable types may be removed.

Artificial and Temporary Shelters.-Where quick results are desired or where conditions are not favorable for growing plant cover, artificial shelters will serve. A simple, though rather temporary, form of artificial escape or loafing cover is the brush pile. In wooded areas with scant undergrowth, the felling of a tree may provide the desired cover at ground level (13). In farming country, orchard prunings can be put to good use. Since a brush pile tends to settle with time, care should be taken to insure enough space beneath for free movement by the quail, if the pile is to serve as loafing cover. A foundation of

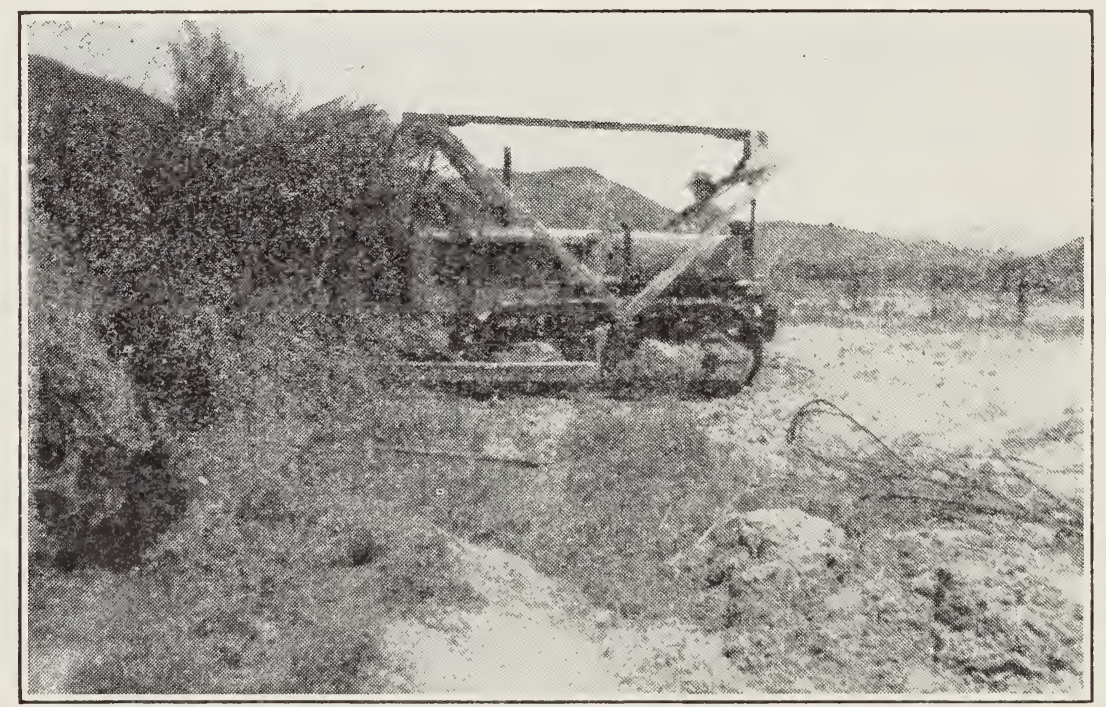

Fig. 14.--Use of a bulldozer for clearing brush lands. (Compare with figures 10 and 11.) The uprooted brush is piled for burning later; small piles may be left as shelter for quail. (Photograph by Cliff Topham.)

heavy branches crossed at right angles will help to keep a brush pile open; but a sturdy, wooden frame, or an old farm gate, supported about 1 foot above the ground, provides a better and more permanent foundation. Figure 13 shows a type of artificial quail cover used successfully in Texas. Brush piles in or near orchards may have to be burned in March, since they may harbor shothole borers and other orchard pests. By that season, however, annual grasses and weeds are generally large enough to satisfy nesting requirements.

Thinning Cover.-In some foothill range lands and along heavily wooded water courses in the valleys, much possible quail habitat is rendered useless by an excess of brushy cover. Even if small populations exist in such areas, they are of little value to the hunter, since they are difficult to shoot. Extensive stands of brush should be broken up into small patches by clearing lanes through them. Once the brush has been removed, annual plants useful as quail foods usually appear quickly, especially where some soil has been turned up.

The surest and safest way to clear brush from the land is to cut and dig it out. This is a slow process, but a few 30 -foot swaths or lanes cut through the 
brush will create much new habitat. A bulldozer driven by a caterpillar tractor is a valuable management tool in country where it can be used (fig. 14). It rips out the undesirable brush and also crudely prepares the soil for food-producing annuals. Various commercial "brush-rippers" and "trail-builders" are on the market, and the efficient "Plumas brush-stripper," developed by the United States Forest Service, serves to clear 6-foot lanes through brush fields. One rancher successfully broke up a dense brush field by rolling the chamise down in winter and then burning in the spring after the brush had dried, but before the annual vegetation was a dangerous fire hazard. His rolling equipment consisted of two 100-gallon oil drums filled with concrete and connected by an axle. This roller, attached to the front of a heavy caterpillar tractor, was pushed through the chamise stands to break off the plants at the ground level or uproot them. Another operator reclaimed chamise land by dragging a heavy "I" beam chained at right angles behind a tractor to grub out the shrubs.

In some foothill areas, especially on extensive north slopes, the stands of Digger pines, blue oaks, and other trees are too dense for good quail habitat. In such areas the trees should be drastically thinned by cutting. Felled trees may be left for temporary escape and loafing cover, if needed, or may be cut into firewood and sold to help pay management expenses.

Controlled burning, under permit, is useful in some places as part of the quail-improvement work. When employed by experienced men, fire can be useful in opening up extensive stands of brush and providing an alternation of brushy and grassy cover. Some brushy species of plants are killed by a thorough burn, whereas chamise and certain manzanitas produce vigorous "stump sprouts" (from the root crowns) after a fire. If not reburned after several years, such growths may again become dense stands. There is much yet to be learned about the use of fire in brushlands. A committee in the California Agricultural Experiment Station has been studying this subject for some years. Under existing laws, the landowner or game manager who desires to use fire in the clearing of brush must first obtain a permit from the State Division of Forestry, and the burning must be done under the supervision of an officer of that Division.

\section{IMPROVING FOOD CONDITIONS}

The whole subject of food supplies and their importance in quail management is imperfectly understood. We know approximately how much a quail requires per day in terms of total quantity and essential food elements, and we know something of the relative desirability of several common foods (8). We do not know, however, just how the population is affected by food surpluses and by ease of access. Studies of the bobwhite quail in eastern and midwestern states point to cover as a primary factor in limiting the increase of that species. Judging from preliminary studies on the valley quail, populations having adequate cover may vary in size directly with the amount and accessibility of preferred foods. This does not mean that food is more important than cover; both are essential. (Anyone who has hunted or observed quail knows that it is useless to look for them in a wheat field where food abounds but brushy cover is lacking.) It does mean the quail populations can often be increased on good habitat simply by supplementing the food supply. $\Lambda$ popu- 


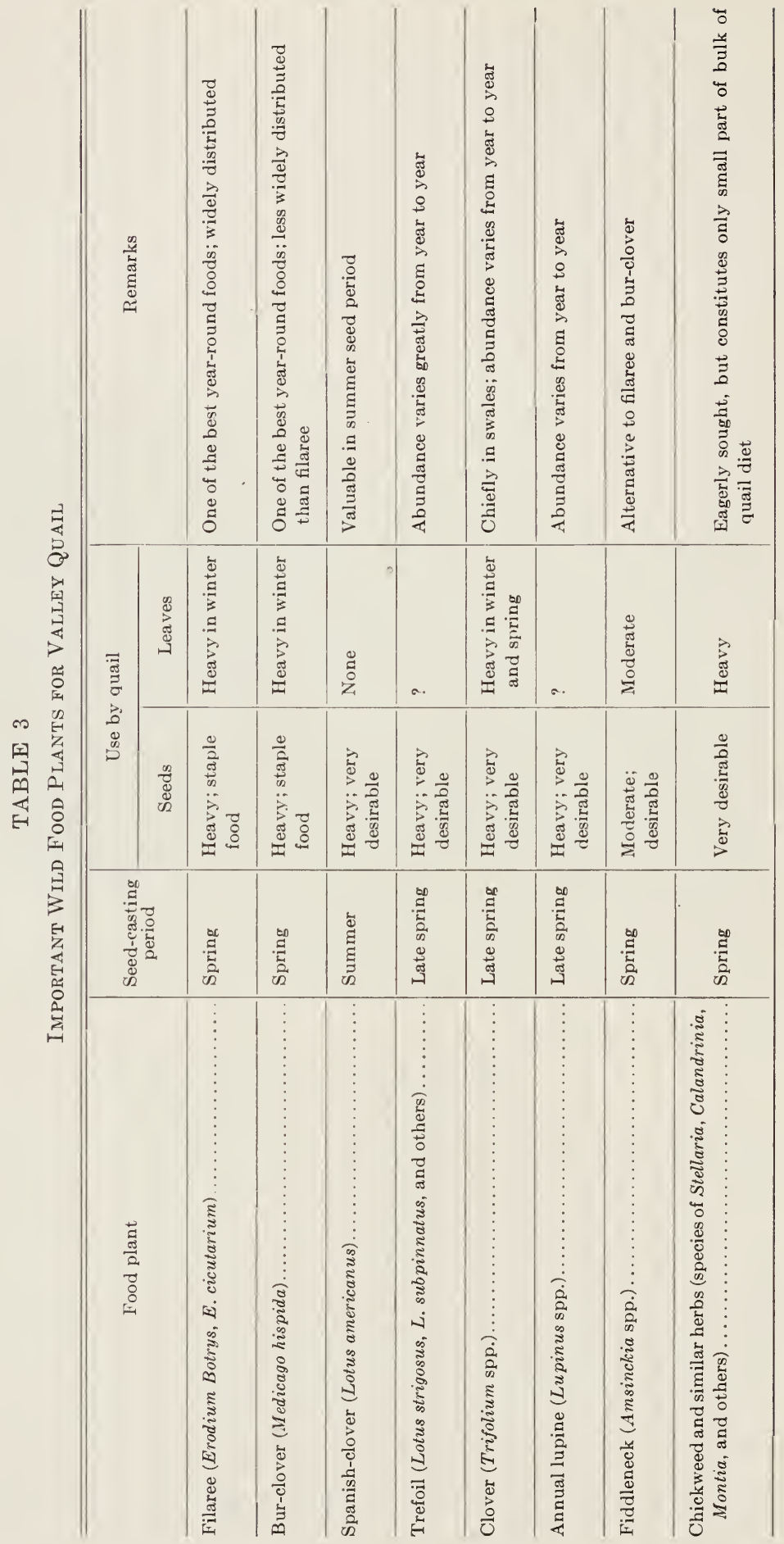


Increasing Valley Quail in CaLifornia

\begin{tabular}{|c|c|c|c|c|c|c|}
\hline 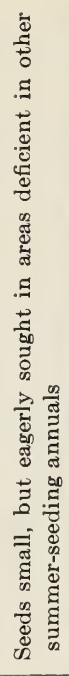 & 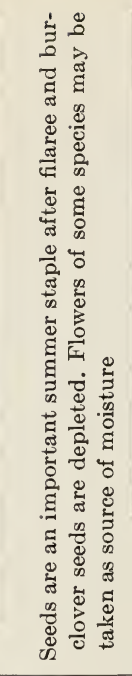 & 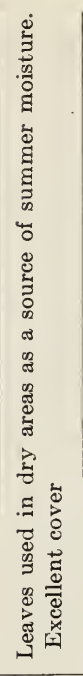 & 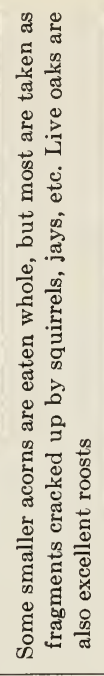 & 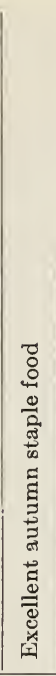 & 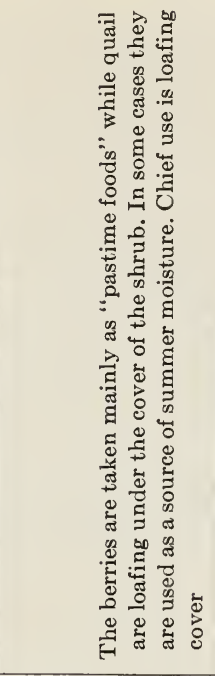 & 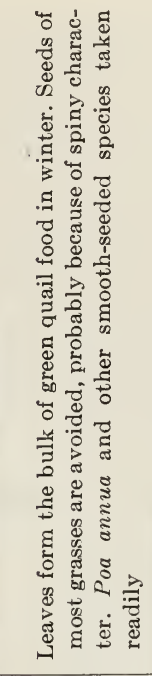 \\
\hline$\stackrel{a}{ }$ & 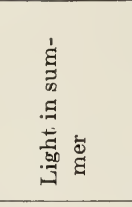 & 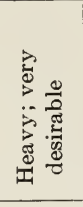 & 气̆ & 芩 & 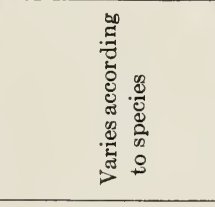 & 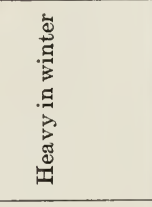 \\
\hline 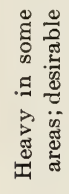 & 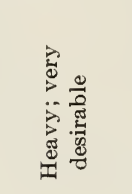 & 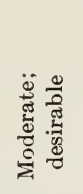 & 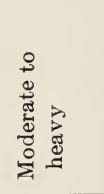 & 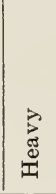 & 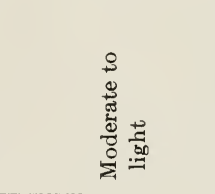 & 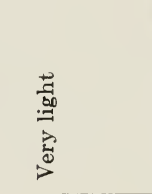 \\
\hline 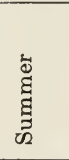 & 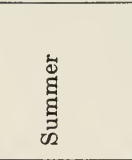 & 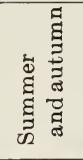 & 吉 & 兘 & 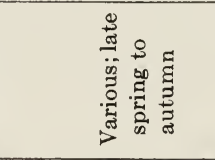 & 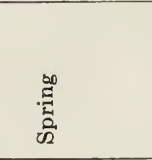 \\
\hline 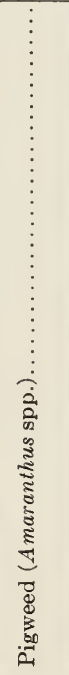 & 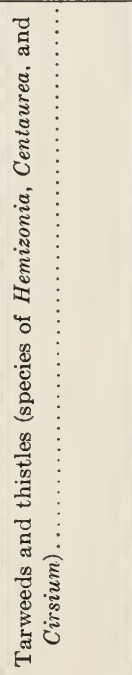 & 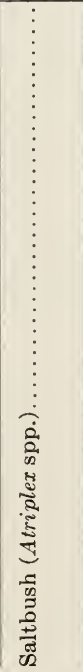 & 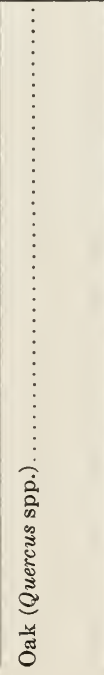 & 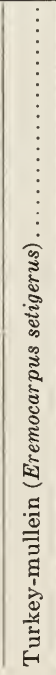 & 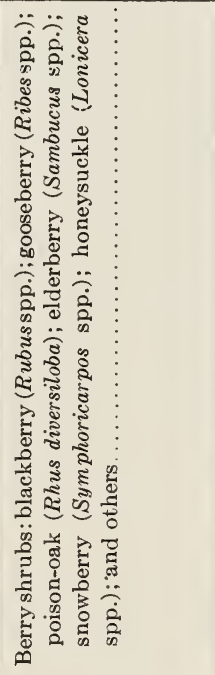 & 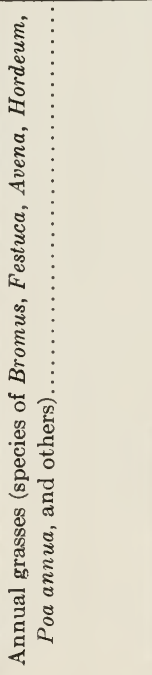 \\
\hline
\end{tabular}


lation of up to 6 quail per acre has been obtained on managed areas mainly by intensive artificial-feeding programs.

Quail Foods.-As a background for planning a food-improvement program, it is necessary to understand the natural food habits and preferences of quail. These birds are almost strict vegetarians, except during the first few weeks of life. Seeds are their chief food during most of the year and are therefore of greatest interest to the manager. Many types of seed are taken. Some of the more important foods eaten by California valley quail are listed in table 3.

The composition of any single quail meal depends on the relative availability and desirability of the foods present. Some definite preferences have been discovered. These quail prefer seeds within a definite size range, from those slight-

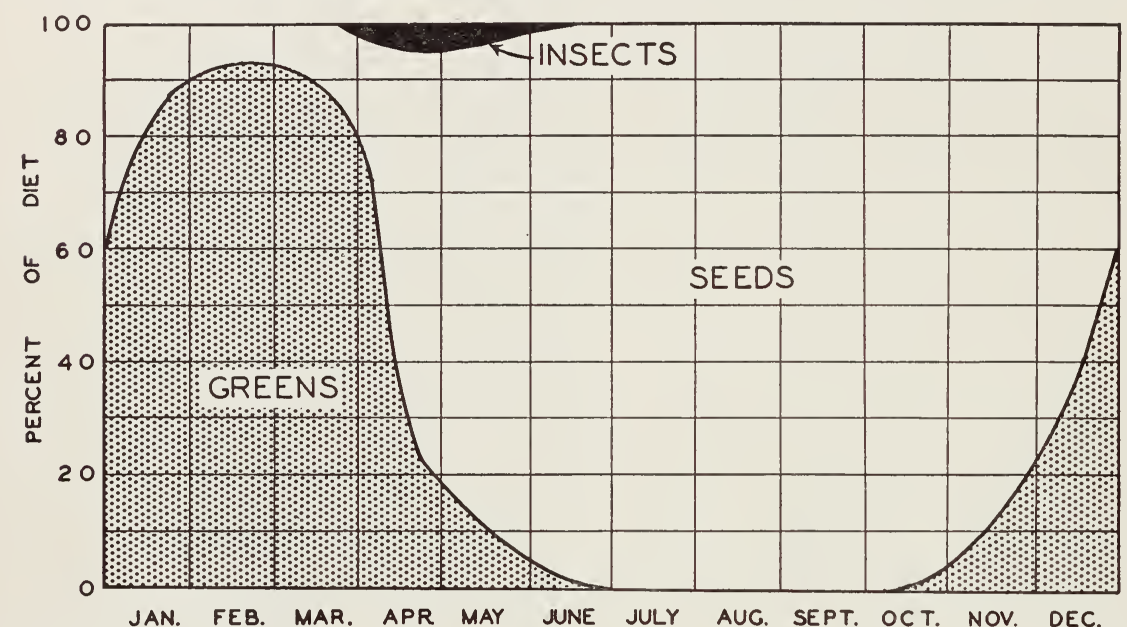

Fig. 15. - The general diet of valley quail in California throughout the year, as determined by various food studies and observations.

ly smaller than a pinhead, such as pigweed and miner's lettuce, to others about the size of a pea. Even smaller items are sometimes taken, and large kernels of field corn or entire small acorns are eaten occasionally. The seeds of most California annual grasses, such as wild oats, foxtail, and the bromes, are generally avoided, probably because of their awkward shapes and sharp ends. The seeds of sweet-clover, mints, and certain other plants are almost never taken, presumably because of undesirable taste. Foods readily acceptable in one locality may be refused when presented for the first time at another place. Often the birds are slow to accept new or strange foods; one should bear this fact in mind when planning a food-improvement program.

The diet of valley quail changes markedly with the seasons (fig. 15), as the various food materials become abundant or scarce. In late April and May, quail feed to a large extent on newly matured seeds of early annuals. A few of these, notably filaree and burclover, furnish seeds throughout the summer; but most annual plants have limited periods of seed shattering and provide food for only a few months. Later-seeding annuals, especially the common clovers, lupines, and trefoils, contribute importantly to the midsummer diet. As these seeds are gradually consumed or lost in the surface soil, those of late summer 
annuals such as tarweed, thistles, turkey-mullein, and Spanish-clover are added to the quail's larder. Few seeds are produced on California quail lands after November 1 ; unless there is still a good supply on the ground at that time, there may be a shortage of food before the autumn rains start the growth of fresh green foods.

In winter and early spring the green leaves of annual weeds and grasses constitute the main source of food. This striking change from seeds to greens probably results largely from the scarcity of seeds in winter, since at that season quail will greedily take grain if offered. On one managed area where seed was provided in quantity throughout the year, there was no appreciable winter shift to green feed.

Food Shortages.-Quail food shortages are of two types: (1) acute shortages of brief duration resulting from snowstorms or floods, or from the sudden destruction of major feeding areas by cultivation or other drastic treatment; and (2) chronic shortages resulting from more or less continuous deficiencies in the vegetation because of unfavorable soil, climate, or land management.

Acute shortages are rare in California. Heavy snowstorms are uncommon on most quail ranges and seldom cover all food supplies for long. In areas where snows present a hazard, as in Lassen and Modoc counties, the survival of a bird population depends on a series of winters of light snows. Floods are usually too localized and short-timed to starve the quail. The destruction of feeding grounds by cultivation rarely robs a covey of more than a part of its range at any one time, except where intensive farming has resulted in a chronic food deficiency and hence a consistently low carrying capacity.

When a sudden, acute shortage occurs, the quail either move out or remain and suffer the consequences. A starving bird is thin, and its flight muscles are reduced until the keel of the breastbone can be felt as a sharp ridge down the middle of the breast. The crop and gizzard usually are empty or contain debris such as twigs and bark.

Chronic food shortages are reflected in low populations rather than in thin and starving birds. They are revealed by examining the nature and composition of the vegetation on feeding grounds. Barren stretches or lands that are intensively cultivated are both obviously deficient in food-producing plants. Other areas of poor food supply may be difficult to detect, especially where the deficiency is slight. On foothill range lands, large, unbroken stands of tall, coarse grasses, such as wild oats and broncho grass or ripgut, are signs of poor local food conditions. Such grasses do not furnish seed acceptable to quail, and in dense stands will choke out the broad-leaved weeds that are the best food producers. The scarcity or absence of staple plants, such as the clovers, filarees, turkey-mullein, tarweed, thistles, and cultivated grains often indicates an inadequate food supply which may become critical in the autumn.

Encouraging Natural Food Plants.-The best quail foods are produced by some of the commonest plants in California. In most places all that is necessary to increase the food supply is to encourage the more valuable species of native plants.

In general, the agricultural soils of high quality produce the best crops of quail food. Acid soils provide few good seed plants, and highly alkaline soils are equally unsatisfactory. Areas deficient in phosphorus will not support bur- 
clover, perhaps the most important of all food plants for valley quail. The spreading of superphosphate fertilizer at the rate of 100 pounds per acre on clearings near good escape cover will often bring notable results on the redsoil areas of the California foothills. Fertilizers containing nitrates should be avoided in a quail-management program, since they tend to encourage grasses at the expense of leafy annuals.

Land-management practices strongly influence the food-producing qualities of an area and often may be easily changed to benefit quail. Intensive cultivation results in chronic food shortages on soils potentially capable of

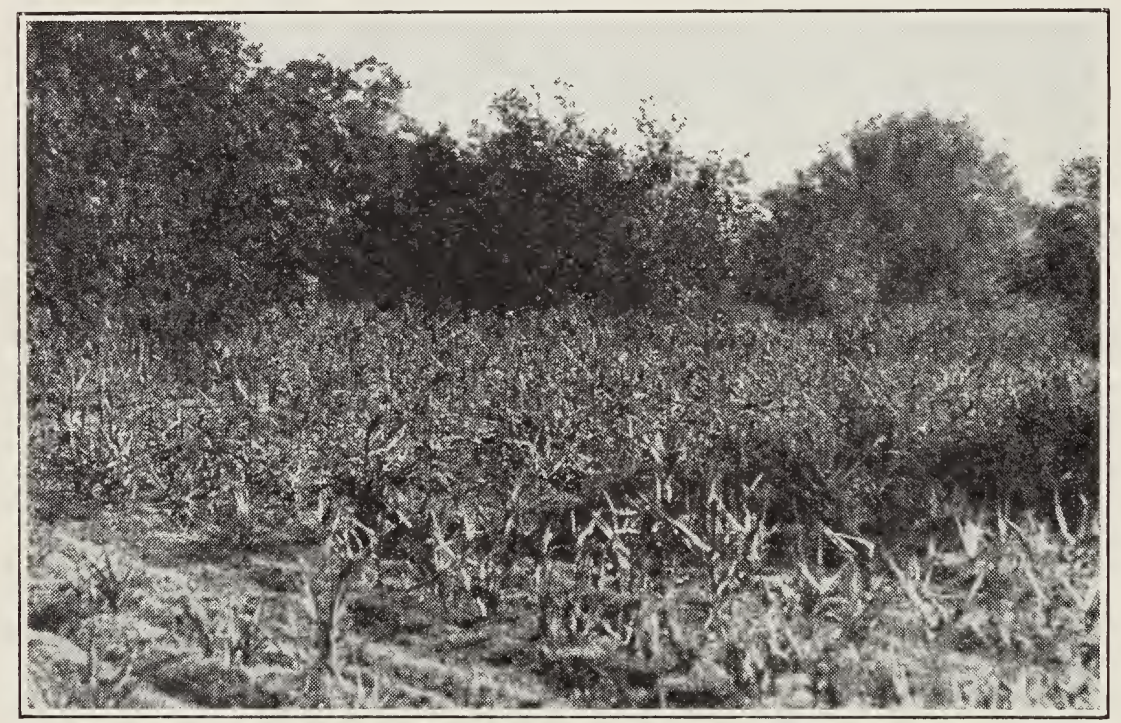

Fig. 16.-A temporary food supply for valley quail-double-dwarf milo as a covercrop in a walnut orchard. The trees are used for roosting by quail in summer, but do not serve as winter roosts. (Danville, Contra Costa County.)

producing abundant supplies. Increasing the quail foods on such areas generally requires nothing more than the retirement of small strips or blocks from crop production. If, in spring plowing, a 20- or 30-foot strip is left along field borders adjacent to hedges or brush patches, the result will be a growth of annual plants, which, under proper management, can provide much valuable food. Leafy annuals may be encouraged by light disking or by burning feed strips just before the winter rains commence. Only a part of the total feeding ground should be so treated at one time, however, for the temporary retirement of a major area might have serious consequences in this critical season. Such treatment, if done by burning, must not be permitted to injure escape cover ; a strip of grasses 1 or 2 feet wide may well be left along brush patches to add to the concealing qualities of the cover.

Livestock graze extensively on many plants useful as quail foods and may seriously deplete the supply by overgrazing. Sheep are particularly destructive, since they tend to browse and graze in close bands that take nearly all food and cover before them. Overgrazing should be avoided at all times for 
the sake of the land as well as the quail. Moderate grazing is rarely detrimental to quail and when properly handled can be an extremely valuable tool of the game manager. Much range land is permitted to grow up to solid stands of wild oats and brome. These areas would be far more productive of quail food if grazed by cattle to a moderate degree in winter and early spring. Where it is impossible to acquire or maintain enough livestock to control the coarse grasses, haying or burning should be employed. If allowed to mature, wild oats and brome grasses quickly lose their forage value and cast seed that will germinate and compete with valuable forage and seed plants. Spot burning, where safe, is excellent for controlling coarse grasses.

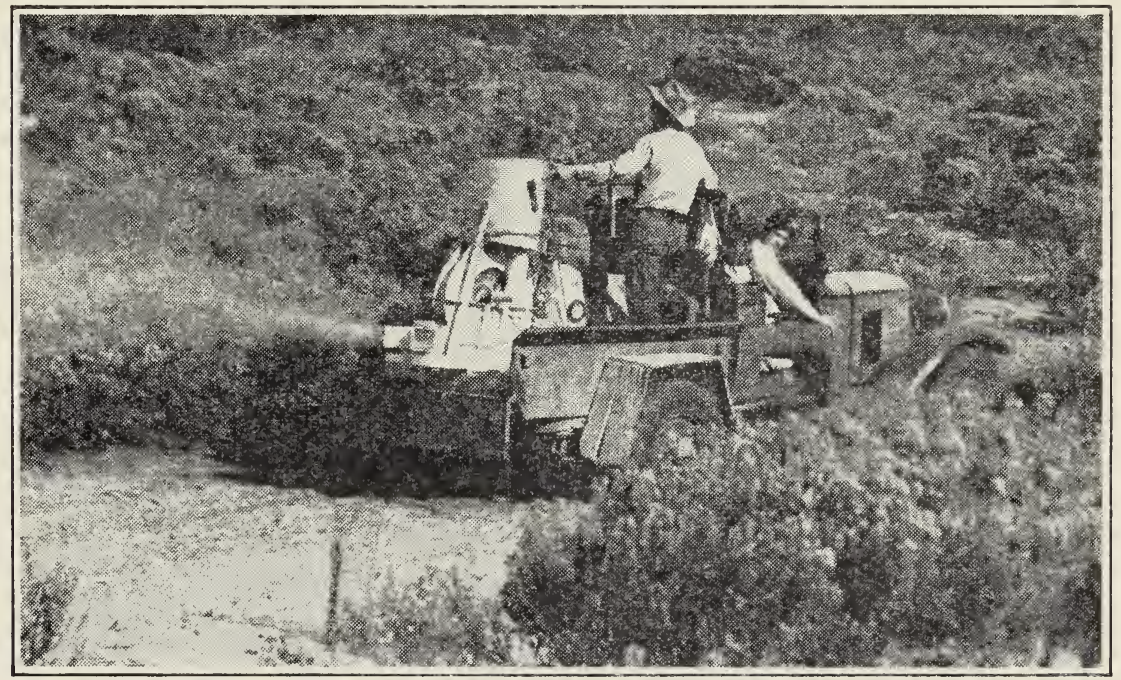

Fig. 17.- Seattering "chick feed" for quail in a brushy area by use of a powerdriven blower. This practice is worth while only on an area managed intensively for quail production. (Dune Lakes, San Luis Obispo County ; photograph by E. Aldrich.)

Planting Quail Food.-It is sometimes advisable to plant food-producing annuals (fig. 16), especially where abusive land practices such as overgrazing have depleted natural food supplies. For maximum use, such plantings should be carefully located with respect to water and cover. Table 4 lists crop plants suitable for California conditions, together with hints for their culture.

Artificial Feeding.-Acute food shortages such as may occur after a heavy snowfall require quick action in the form of artificial feeding. Feeding spots must be carefully selected with respect to escape cover and the known feeding areas of local quail. Patches of ground 6 to 10 feet in diameter should be cleared to display the food, to expose any natural food present, and to attract the attention of the birds. Feed casually thrown on deep snow is usually overlooked by quail.

Regular year-round artificial feeding has been practiced on several private game areas with notable success. One group of sportsmen has built up a population of over 2,500 quail on a 400-acre tract by distributing 500 sacks of grain per year. Less ambitious feeding projects have also given good results. The practice is always costly, however, and can be recommended only where cover 


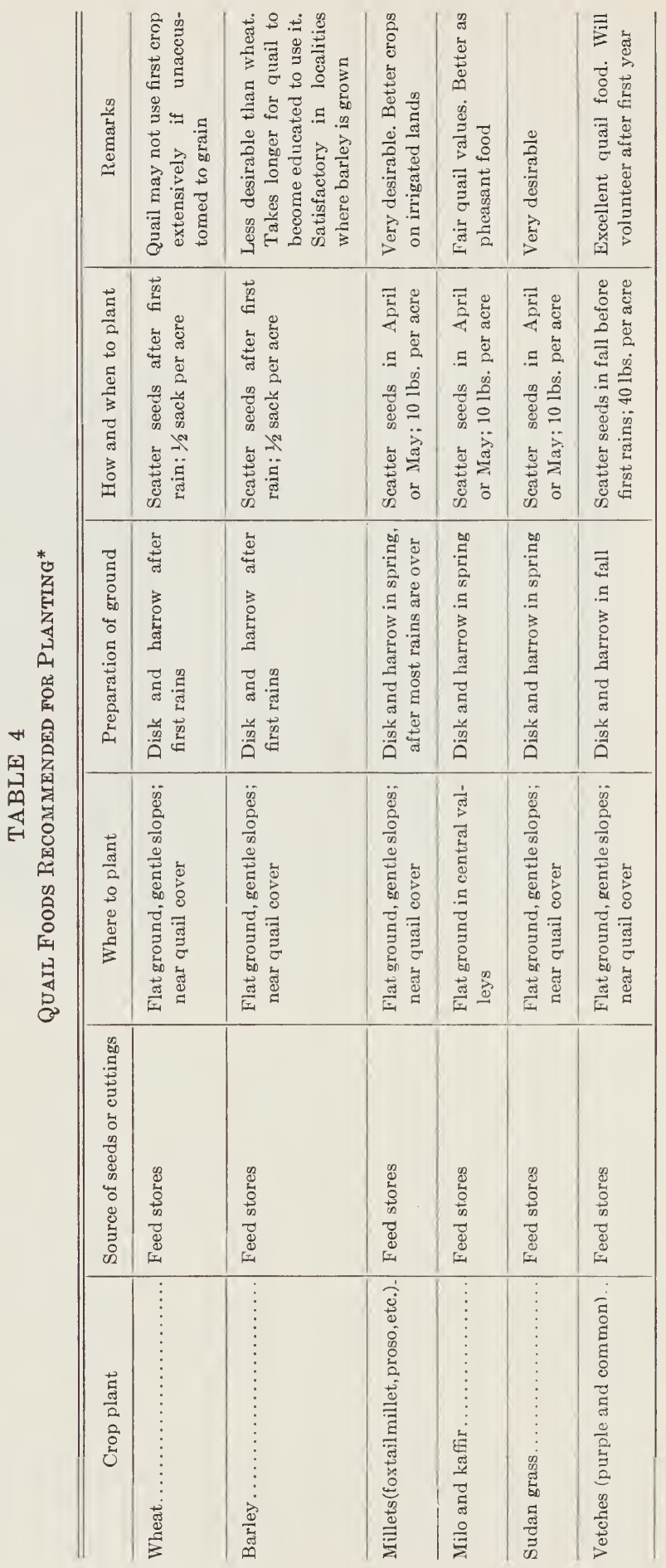




\begin{tabular}{|c|c|c|c|c|c|}
\hline 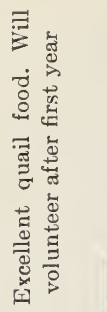 & 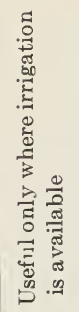 & 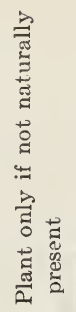 & 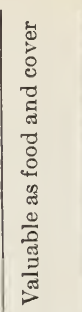 & 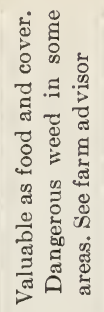 & 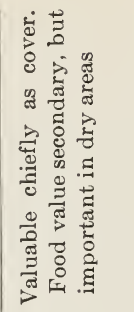 \\
\hline 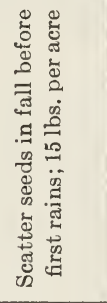 & 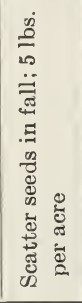 & 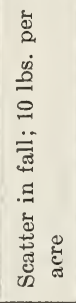 & 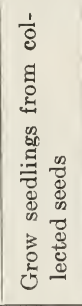 & 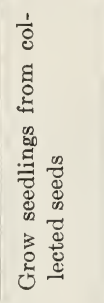 & 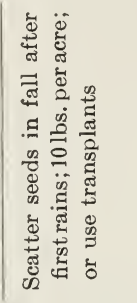 \\
\hline 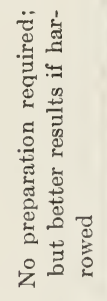 & 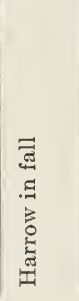 & 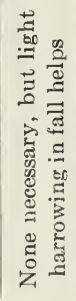 & 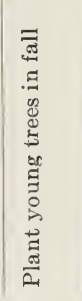 & 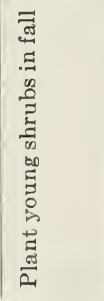 & 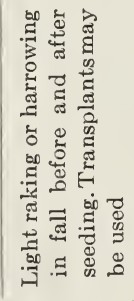 \\
\hline 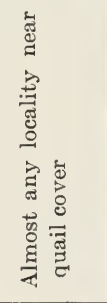 & 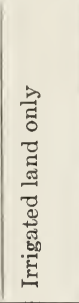 & 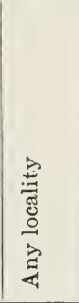 & 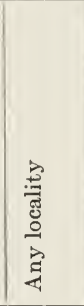 & 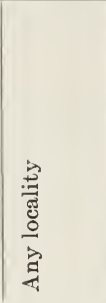 & 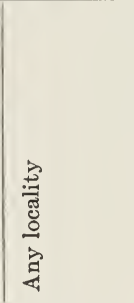 \\
\hline 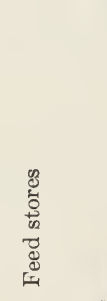 & $\begin{array}{l}0 \\
0 \\
0 \\
0 \\
0 \\
0 \\
0 \\
0 \\
0 \\
0 \\
0.4\end{array}$ & 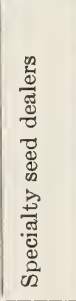 & 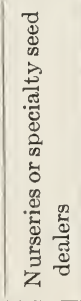 & 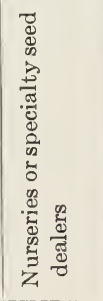 & 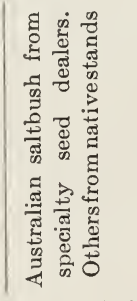 \\
\hline 今̊ & 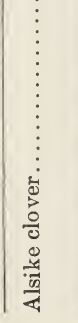 & $\begin{array}{l}\stackrel{0}{0} \\
\frac{5}{5}\end{array}$ & 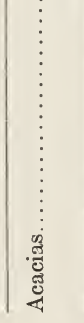 & 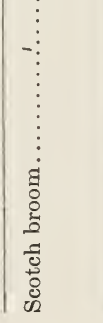 & 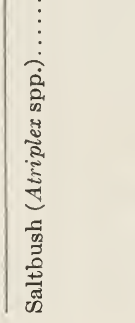 \\
\hline
\end{tabular}


and water have been developed to the limit and are known to be adequate for a heavy population.

Almost any common grain when ground to suitable size is satisfactory for quail. Commercial "chick scratch" is excellent. If such ground or cracked feed is not available, quail can usually be educated to accept the smaller whole grains such as millet, milo, and wheat. Even such coarse grains as whole barley are taken where quail are accustomed to such foods. Harvest screenings are often satisfactory and are inexpensive. Such screenings should be used, however, only in the locality from which they were acquired ; if transported elsewhere, they may spread noxious weeds.

Feed should be distributed several times a week throughout the year or during the local season of shortage. It should be scattered in places well supplied with loafing and escape cover. Rodents, always troublesome on artifically fed areas, are particularly so when the grain is allowed to fall in piles. A seed broadcaster towed behind a car is a practical means of distributing quail feed. One sportsmen's group has had great suceess with a homemade blowing device mounted on the bed of a pickup truck (fig. 17). The grain is blown out into the brush for a distance of 20 to 30 feet as the vehicle moves slowly past the selected feeding areas. Since quail populations supported by artificial feeding will suffer severely upon any temporary suspension of operations, negligence must be avoided.

\section{IMPROVING WATER CONDITIONS}

Water Requirements.-Water is a fundamental requirement of life; quail cannot live more than a few days without water in some form. During the winter, it is widely distributed and available in pools and streams and in the abundant, succulent, green vegetation. In summer, however, the scarcity of water over large tracts is a major factor in limiting quail populations. Occasionally, small coveys are encountered in waterless areas of the coastal belt, where the summer fogs leave moisture on the vegetation almost every morning. In other parts of California, some quail maintain themselves on the succulent berries of honeysuckle, gooseberry, and redberry, and even on the blossoms of certain summer annuals. These are poor substitutes for drinking water, however, and most of the birds will emigrate from a poorly watered area as the springs and streams dry up.

Newly emerged chicks cannot travel more than a few hundred yards from their hatching places without water. Nests built during the season of green feed, when moisture is abundant, may be far from water when the chicks hatch. Such broods are doomed to die.

In arid regions quail tend to concentrate around persisting water holes in late summer until many hundreds may be crowded on a few acres. Such undesirable concentrations overtax the carrying capacity of the local area and expose the birds to increased danger from predators and disease. Large numbers of quail are slaughtered by pot hunters at water holes in years when the autumn rains are delayed until after the opening of the hunting season.

Providing Water.-A wise distribution of supplementary watering places is the most important and effective way to increase quail on arid lands.

The simplest improvement is to dig out semipermanent springs and seeps so that they will supply water throughout the summer. Such sourees should be 
permanently developed wherever possible by boxing with redwood or concrete and fitting float valves to conserve water for the quail. A standard float-valve installation for this and other uses is shown in figure 18.

Existing pipe lines sometimes may be tapped, and a float-valve device installed. If water conservation is not a deciding factor, a dripping valve may sometimes be used. This arrangement has given great success in the Kettleman Hills, where oil companies have permitted the tapping of their water lines for the purpose.

Existing stock troughs can provide excellent watering places for quail as

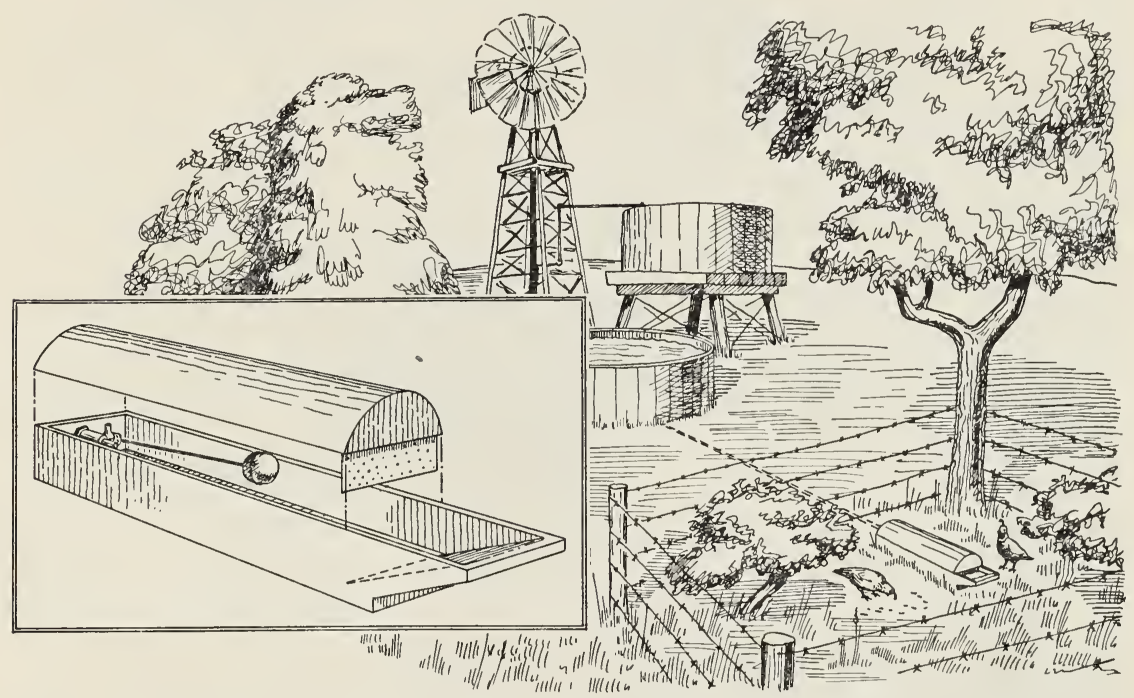

Fig. 18.-Float-valve water trough for quail. The trough is supplied either through a pipe from some existing source (for example, a cattle tank) or from a storage tank especially provided. The inset figure shows the details of construction, the cover being raised to reveal the ball float and valve.

they are or with a few improvements. Often because of the trampling by stock, a fenced enclosure or the planting of stock-resistant brush will be needed. The tall, steep walls of some troughs are both a handicap and a hazard, especially for young quail. This condition can be remedied by providing a wooden ramp with cleats up to the edge of the trough and a ramp of wire screen down into the water. A plank floating in the trough can serve as a convenient platform for the drinking quail. Where water is abundant, a copper tube bent as a permanent siphon over the edge of a trough and pinched at the lower end to release a trickle to the ground, will make the supply readily available to chicks. In a better and more permanent arrangement, a " $\mathrm{T}$ " is inserted in the pipe inlet to the tank, and some water is taken off into surrounding cover or into a cattleproof enclosure through a length of pipe, connected to a float-valve installation or to a dripping valve and trough.

Much land on which quail might live has no trace of water during the summer. Such lands need quail-watering installations connected with storage tanks that are filled at regular intervals throughout the summer or that have rain-collecting devices (figs. 20 and 21 ). 
The "dew-dropper" (16) comprises a 50-gallon oil drum with a 3 -foot length of $3 / 4$-inch pipe fitted into its small opening. The lower side of the pipe is tapped at regular intervals and fitted with ball valves or oil pressure-lubrication fittings from which the springs have been removed; and the pipe is capped at its far end. These "dew-droppers" are recommended only where they can be watched and filled frequently; if the water contains much mineral, the valves become encrusted with precipitate and will stick either open or shut. Unfortunately, in areas where these installations are most valuable, the water

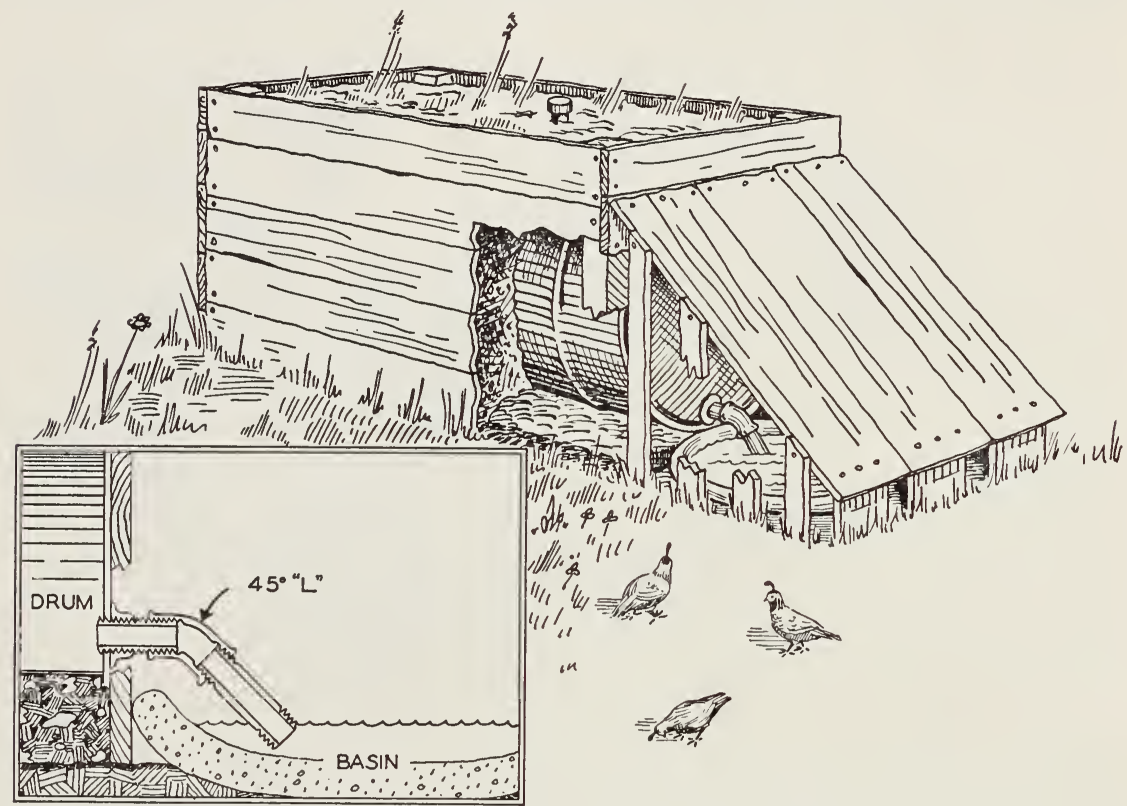

Fig. 19.--Vacuum type of quail-watering device. Earth is filled in around the storage drum in the box to insulate against summer heat. The outlet discharges into the concrete drinking basin under the lean-to shelter. The lower end of the outlet pipe must be closed with a cap or cork when the drum is being filled. The filler eap on the top of the drum must be sealed airtight after filling.

available to fill them contains much dissolved mineral matter. There is some question, too, as to whether these dropping devices are used by young quail.

The "vacuum type" trough is a more satisfactory unit, using a 50-gallon drum (fig. 19). The plug in the upper large opening is sealed with white lead or waterproof grease, and the lower opening is connected to a $3 / 4$-inch pipe leading down into a concrete basin. Several precautions must be observed: (1) The tank must be absolutely airtight and watertight. (2) The tank must be well shaded or, better still, buried in a bank of earth or a dirt-filled box so that the daily expansion and contraction of the air within will not pump all the water out in a few days. (3) The outlet pipe must not include any long pieces of horizontal or back-sloping pipe, because "air-locks" will form. (4) A surrounding apron of rocks or concrete is needed to keep rodents from scratching dirt into the trough. This last precaution should be taken with all types of troughs described. 
A float valve may be installed with a storage tank although such a unit is more effective if a greater head of water is provided than that furnished by a 50 -gallon drum at valve level. On one ranch excellent results were obtained with a float-valve unit and 400-gallon tank which was equipped with a collecting apron for automatically refilling the tank from rain water.

Several different "self-filling" watering devices have been designed. The

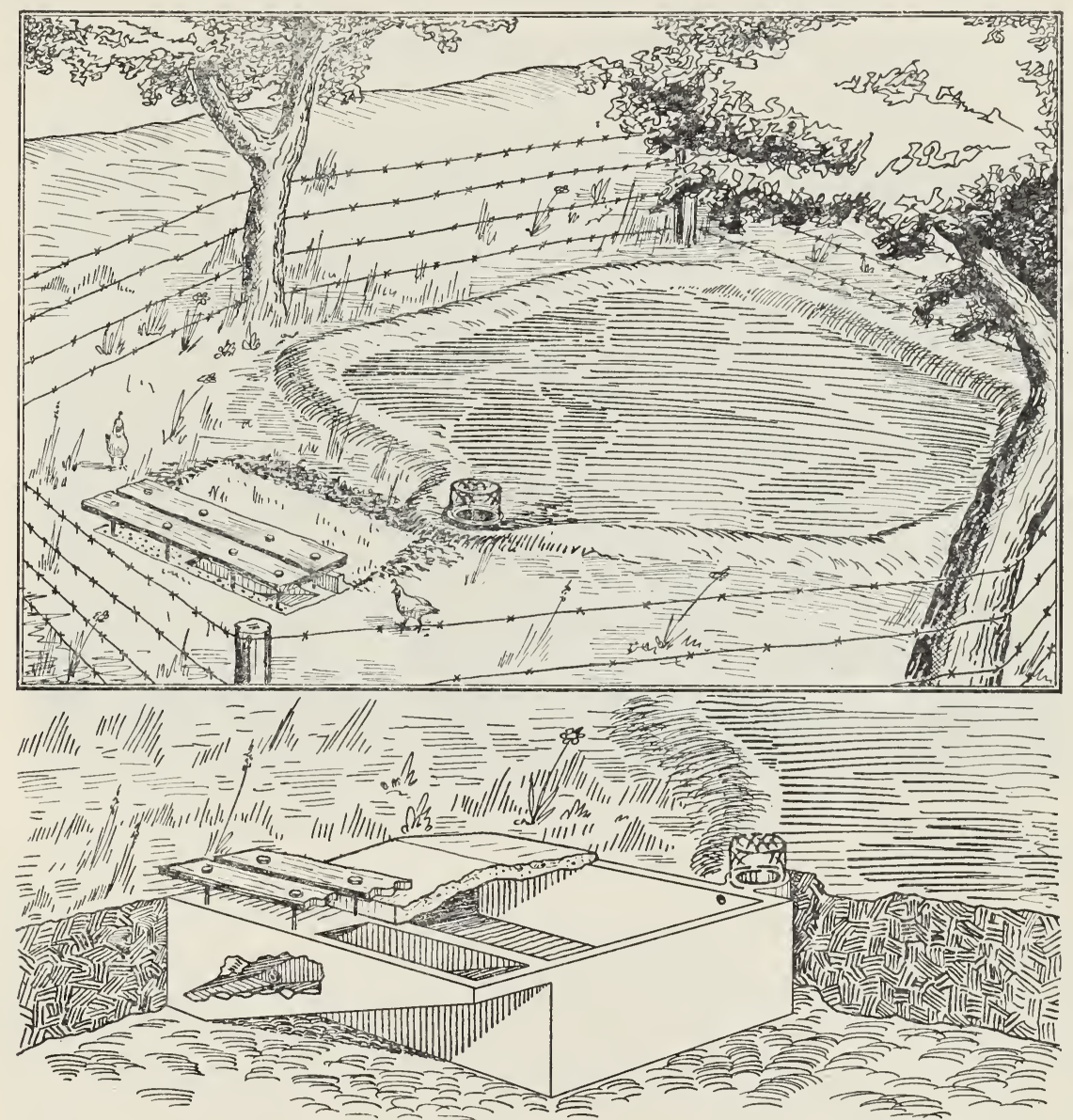

Fig. 20.-Quail-watering device ("gallinaceous guzzler"). The collecting apron of oiled earth slopes and delivers water into a concrete storage tank, buried in the ground between the apron and the shaded drinking trough shown at the left. In the lower view the dirt has been cut away to show details of the tank.

winter rainfall is gathered by a collecting apron and led into a storage tank for summer use. The least expensive and most satisfactory collecting apron is made by scraping the vegetation from a small area slightly uphill from the storage tank and treating the cleared ground with thin road oil. Such an apron with an oiled earth crust about 1/2-inch thick is efficient if protected from trampling stock by a fence. The apron should be of such an area that about half of the minimum annual rainfall for the locality will fill the tank; in a 
region having a minimum rainfall of 6 inches per year, a 400 -gallon tank will be filled by 3 inches of rain falling on an apron of about 215 square feet. Concrete aprons can be used, but installation costs are higher than with those of oiled earth. Collecting areas may also be made of sheetmetal; these, however, are more liable to destruction by vandals.

The collecting apron is particularly well suited for the installation known as the "gallinaceous guzzler" (6). This comprises a subsurface concrete tank,

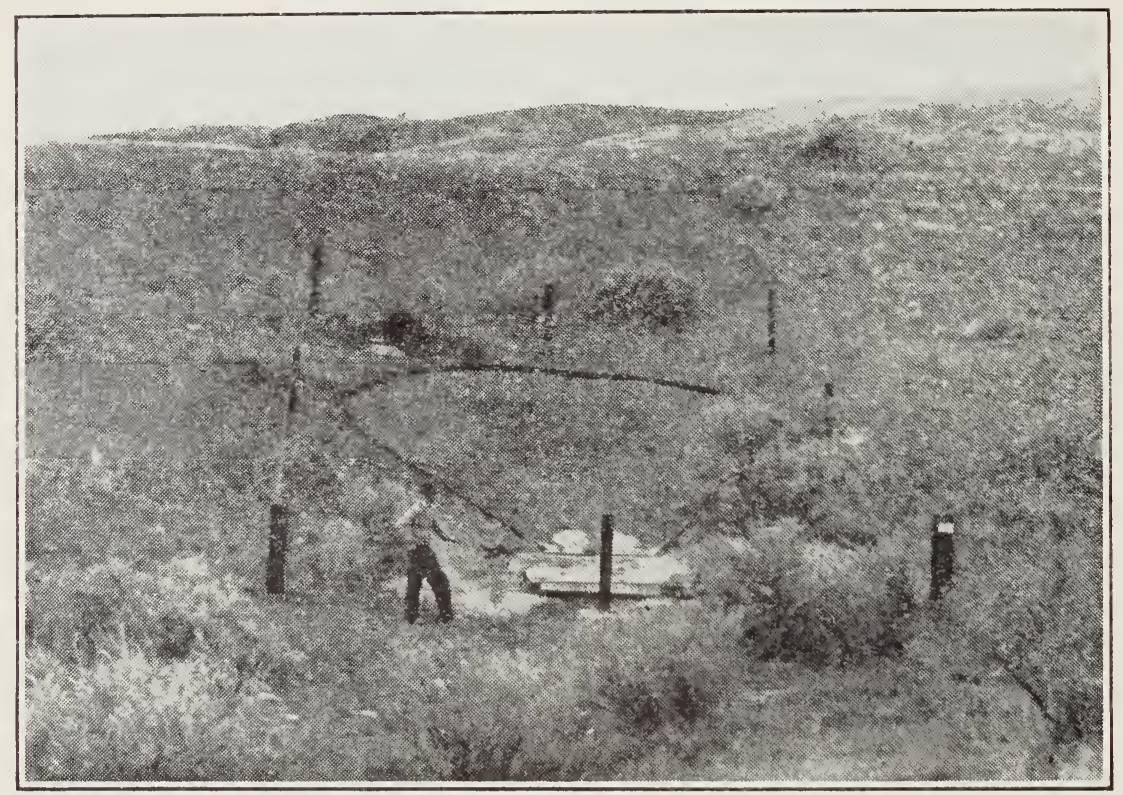

Fig. 21.-General appearance of the watering device of figure 20 as installed. The 3 -strand barbed wire fence excludes domestic livestock. (Kettleman Hills, Fresno County.)

permanently covered to prevent evaporation or access by animals, and connected at the bottom to a drinking trough sloping up from the bottom of the tank to the ground level (figs. 20 and 21). $\Lambda$ s the water is gradually used, its level lowers in both tank and trough, and the quail follow the receding water down the slope. $\Lambda$ combination shade and large-animal guard is made of $2 \times 10$ inch redwood planks bolted over the drinking trough. This unit has the great advantage of requiring no attention save an occasional cleaning.

\section{PROTECTING QUAIL POPULATIONS}

Like any other species with a high reproductive rate, the valley quail has a high mortality; in any stable population the losses of a single year must approximately balance the reproduction. If every pair of quail were able to hatch a full clutch of 15 eggs and raise all the young to maturity, the quail population would increase about eightfold every year. In reality, however, predators, disease, accidents, and hunters remove the surpluses each year after they are produced. Detailed studies of wild quail populations show that a great majority of the potential crop of young fails to appear or succumbs 
by the first autumn, and that more than half the adults in most areas die off every year.

One important phase of quail management is to protect the surplus produced during the breeding season, but practical protection has several limitations. In the first place, continuous attention is required for success. Habitat improvement (see the section "Improving Land for Quail Occupancy") is the offensive arm of a management program capable of making new and permanent increases in the breeding stock; protection is a defensive activity, a fight to reduce the normal pressure constantly exerted on a population by its many

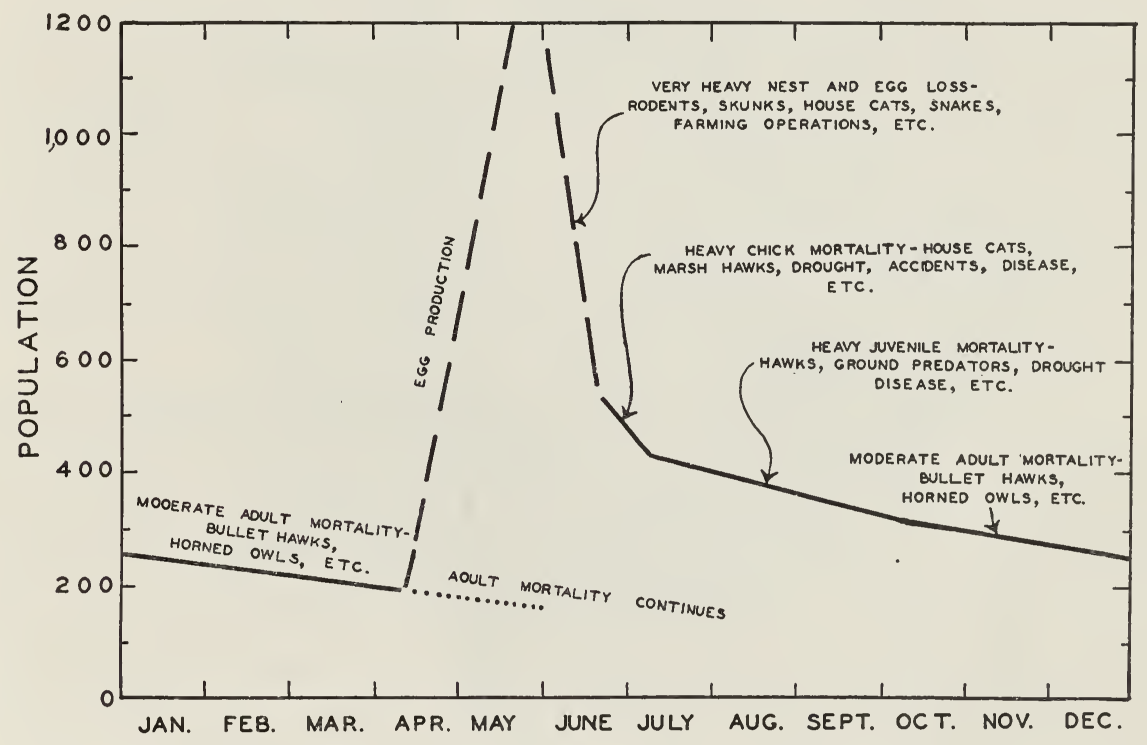

Fig. 22.-Diagram of the annual rise and fall in a population of valley quail and some factors that influence the seasonal changes in numbers. The population figures are approximate for a section of land, 640 acres.

enemies. Proper protective measures can materially reduce the mortality on a quail area and yield a substantial increase. There is good evidence, however, that a quail population permitted to surpass the carrying capacity of its range is more available to the persisting predators, more subject to uncontrollable disease, and more prone to accidents. There is a normal balance between any animal population and its enemies on a given area; nature tends to right this balance whenever it is artificially disturbed and acts quickly to cancel the gains made by a protective program, once the manager relaxes his activities. This should not discourage quail protection, for well-planned control of predators and accidents often can provide a substantial surplus for the shooting season. To conduct an effective program successfully, the manager must clearly understand the normal types and causes of quail mortality. These are shown in figure 22.

The heaviest losses are those among eggs and chicks. Nearly all the adult females lay at least one set of eggs during each nesting season, except during extreme drought. Only a few of these clutches, however, survive without loss 
until hatching time. For example, of 96 quail nests studied in one year on range lands in the foothills of Madera County, only 17 were successful; all the rest were destroyed by rodents, snakes, carnivores, or livestock, or were deserted (4). In farming areas the damage to nests is also high as a result of cultivation, mowing, and irrigation. Fortunately, quail are persistent in their nesting activities and will seldom give up after a first failure. For this reason, although they rarely produce more than one brood in a season, a reasonable number of females, perhaps up to one third of those in some areas, eventually achieve success.

Having hatched and thus cleared the first obstacle in the struggle for survival, baby chicks are confronted with a new array of dangers which, within the first 2 weeks, claims a quarter or more of their number. In places, flesheating ants are serious enemies of the helpless young as they emerge from the shells. Some flightless chicks fall easy prey to various ground predators, which may consume an entire brood. Still others fall into holes, become entangled in plants, are drowned, or get lost while too young to fend for themselves. Those young that survive the critical flightless period, however, are relatively safe; chick mortality declines sharply after the second week and then follows a course resembling that of adults (fig. 22).

In one observed population, the natural mortality among adults in winter averaged about 7 per cent each month (3). Assuming this to be typical, an October covey of 30 birds, undisturbed by hunters, loses about 2 birds a month and enters the next breeding season with 20 birds, or 10 pairs. Summer mortality among adult males continues at about the same rate, but among the females is considerably increased because stealthy terrestrial carnivores, such as house eats, foxes, and weasels, find these ground-nesting birds easy prey. By the next October, the original group of 30 adults has been reduced to about 12, perhaps 7 males and 5 females. Meanwhile about 18 young have been added (the surviving progeny of 3 females), bringing the covey back to a total of 30 birds (fig. 22).

The principal causes of quail mortality and the methods for reducing losses may be grouped under the headings of "Predators," "Diseases," and "Accidents."

\section{PREDATORS}

Predators are probably the chief natural cause of the mortality among valley quail. Well-planned predator control can save a considerable number of birds for sport and enjoyment. To be effective, however, the program must be concentrated locally on the quail area and must be aggressive and persistent, yet carefully selective. If properly done, it is an expensive activity, advisable only when the manager is certain that he is doing everything practical to develop quail habitat.

Indiscriminate destruction of predators, as attempted by many enthusiastic and well-meaning groups, is not effective control; these typical short-lived campaigns over an entire township or county do no lasting good, since only a small percentage of the predators living on the tract are ever eliminated and since the normal increase and migration of survivors quickly cancel the small gains made. Furthermore, such efforts usually include any and all hawks and owls, many of which are beneficial rather than injurious to game-bird popu- 
lations. Although the numbers of useful birds destroyed by such ill-advised campaigns are probably not large enough to do much permanent harm, it is deplorable that sportsmen fail to recognize their natural allies.

Many predators are of value because they destroy rodents that rob nests and consume quail feed. Most of the 33 kinds of hawks and owls that occur in California subsist mainly on rodents ; only 4 normally feed on quail to an appreciable extent. The barn owl, most frequent victim of haphazard campaigns, feeds almost entirely on small mammals that compete with quail. On one inten-

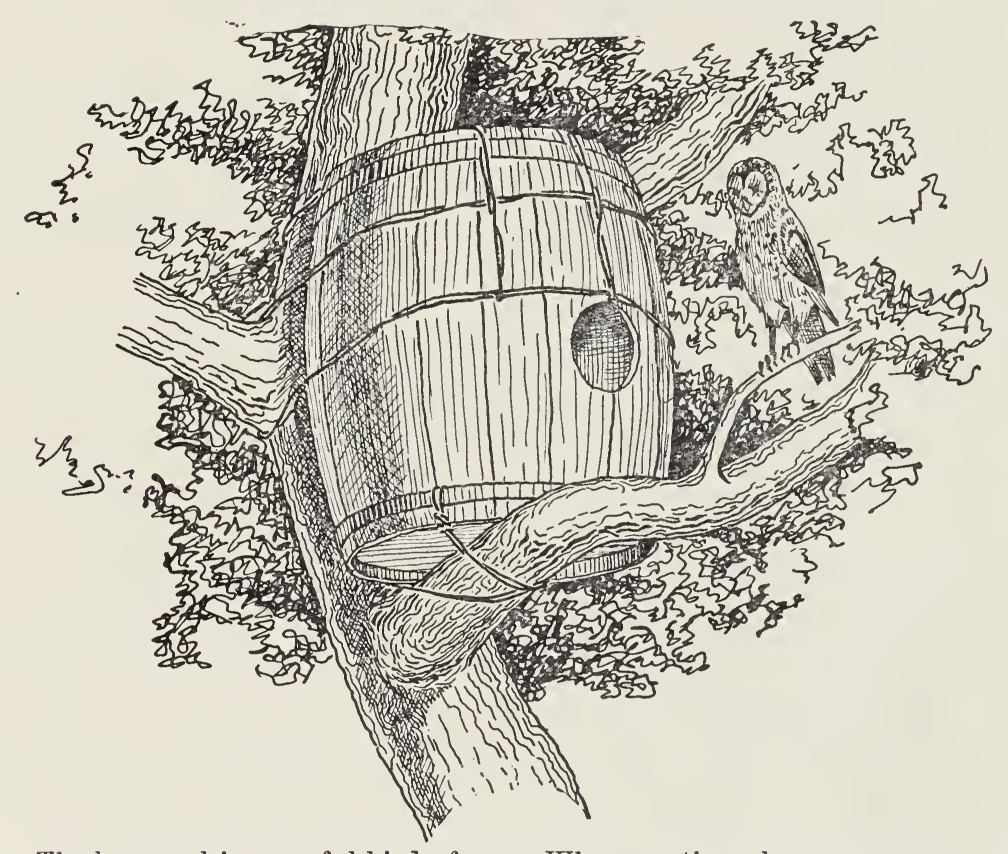

Fig. 23.-The barn owl is a useful bird of prey. Where nesting places are scarce, a wooden barrel wired into a tree will provide a suitable place for the owl to roost and nest.

sively managed quail preserve, the remains of 933 barn-owl meals included only 2 quail, both chicks. Studies have shown that a single barn owl can take more than 4,000 mice from its beat in the course of a year. Such a bird should be rigidly protected and even encouraged on a quail range. Roofed wooden boxes or small barrels provided with a 4 - or 5 -inch entrance hole make excellent shelters and nesting sites for barn owls when placed on poles or wired in trees at 10 to 15 feet above the ground (fig. 23). The establishment of such boxes helps in quail conservation.

Quail predators may be divided into two major groups : the ground dwellers such as carnivores, rodents, and snakes, which are destructive primarily during the nesting season; and the hawks and owls, most harmful during the winter.

Ground Carnivores.-Being limited in their habits and hunting methods, the ground carnivores do not endanger fully grown quail that are physically sound, except under special conditions of deficient cover. Incubating birds, as already noted, suffer heavily at times; and an occasional roosting quail may be surprised in its sleep by a stealthy cat or weasel. Crippled birds, unable to 
fly, are usually devoured by the first cat, coyote, or fox that comes along. Many young chicks may be killed before they develop powers of flight.

The chief damage done by carnivores, however, is to nests and eggs. Many a nest is broken up in attempts to catch the incubating hen, and others for the eggs alone. Most nest predators leave characteristic traces by which a careful observer may identify them. Skunks crush in the side of each egg to suck out the contents, and leave the shells in or near the nest. Coyotes, foxes, and dogs generally chew up the eggs, leaving only a few shell fragments. House cats usually crack the eggs roughly and lick out the contents, leaving roughly broken shell particles.

Cover is of limited value as protection for quail against ground carnivores. Very dense cover may even increase the danger by serving as a screen for stalking predators. The quail seem to be aware of this, because a covey will normally stay in the open when a cat is near by. Quail rarely build nests in dense brush, and nests in the open evidently are the most secure from terrestrial predation.

The best defense against ground carnivores is, first, to be sure there is adequate open nesting cover available and, second, to keep down nest predators by trapping and shooting. The maximum return in quail protection will be gained if the trapping is started in January, before the carnivores begin to breed. The pelts then are still prime, and some cash return may be had from those of skunks, bobcats, and raccoons. Cats that have gone wild are usually the most destructive of ground carnivores, since their depredations continue the year around; they should be hunted down relentlessly. Opossums, which have been introduced into California and have spread over large areas, are a menace that should be checked.

Rodents.-Field rodents affect quail populations by raiding nests and also competing for food. As nest raiders they are efficient and secretive, leaving few traces. Ground squirrels cause heavy losses. Of 292 nests studied at the San Joaquin Experimental Range in Madera County during a 4-year period, one-third were destroyed by ground squirrels; the latter did more clamage of this kind than all other predators combined. Parent quail will viciously attack a marauding squirrel, but to no avail. The squirrel removes the eges one at a time until, within a day or two, all are gone with scarcely a displaced grass blade as evidence. House rats and chipmunks will rob the nests and may be of local importance if present in numbers. Some of the larger mice also have been reported to take the eggs.

Seed-eating rodents may be direct competitors of quail where limited food supply is a factor in preventing quail increase. This relation becomes obvious when artificial feeding is practiced, and both rodents and quail are attracted to a small area. Food competition under natural conditions is difficult to determine and evaluate. We know, however, that rodents consume much filaree, bur-clover, and other favored quail foods.

There is good evidence that removal of ground squirrels in heavily infested areas will result in an increase of quail. Several well-tested control measures are possible against squirrels (19), but on quail-management areas, one must be selected which will be effective without endangering the birds. Where economically possible, the best procedure is gassing with carbon disulfide or some 
other standard rodent fumigant. This has the advantage of killing only the squirrels and other animals living in their burrows.

If a poison must be used, the operator should limit himself to strychnine in doses recommended by the California State Department of Agriculture and the county agricultural commissioners. The fatal dosage of strychnine for squirrels is entirely harmless to valley quail ; the authors have experimentally fed captive quail entirely on strychnine-coated squirrel bait for long periods, and have yet to see a quail killed by it. Since, however, strychnine will kill doves, cottontails, and some other game, its use must be limited where the manager must also consider those species.

Thallium-treated grain has become popular as a rodent poison during the past decade and has been used extensively by government agencies. It is highly poisonous to quail in the dosages employed for squirrel control. When used in areas where quail regularly feed on cultivated grains, losses of quail are to be expected. If the game crop is a consideration, thallium should not be used.

Recent developments in rodent control promise to solve many of these difficulties. The use of colored dyes on rodent poisons is one of the new techniques. Rodents, being color-blind, accept these dyed grains, whereas birds generally avoid them. In addition, some new chemical compounds developed during the war are useful in control. The game manager should consult the local agricultural commissioner for the latest developments in this field.

Snakes.-Although snakes are known to destroy quail eggs, their real significance as nest predators is not clear; they enter nests, swallow the eggs entire, and depart, leaving little evidence except the disappearance of the eggs. Gopher snakes and king snakes have often been caught actually robbing the nests. Effective control, however, is difficult. A snake population probably suffers during a rodent-poisoning campaign : many are killed by eating poisoned squirrels, and the drastic reduction of their staple food supply (rodents) presumably has some additional effect.

Hauks.-Of the 20 species in California, only 3 prey importantly on quail (fig. 24). These are the sharp-shinned hawk, Cooper hawk, and marsh hawk. The first two, commonly known as darter or bullet hawks, are serious enemies in winter, when considerable numbers occur over quail range. In summer they are comparatively scarce in quail country.

These two liawks have short, rounded wings and long tails; and they stay close to cover as they forage. They are similar in appearance, but the Cooper hawk is larger and hence more destructive. Bullet hawks usually watch from some partially hidden perch, waiting for an opportunity. The catch is made with a swift, silent approach; should the hawk miss on the first pounce, there is a headlong chase. This method is very effective for catching birds in the open brushlands, the natural habitat of quail. The manager can expect to lose quail to these skillful hunters wherever they occur, especially where escape cover for quail is inferior or inadequate.

Marsh hawks, though present throughout the year, are important only as quail chick predators. They hunt on the wing, slowly beating back and forth just over the grass tops until they surprise some mouse or small bird on the ground. The pounce is quick and accurate. Adult quail, with their preference for open feeding grounds near brush, are seldom bothered by marsh hawks; 
but the chicks, unable to dodge a quick approach, are ready victims. Food items brought to one marsh hawk nest on a quail preserve included 22 per cent of quail chicks.

Most of the other California hawks may take quail on occasion, but not in significant quantities. The large, soaring types, commonly misnamed hen or chicken hawks, feed primarily on rodents and as such are allies of the quail manager. They are usually too slow to capture quail where the cover is ade-

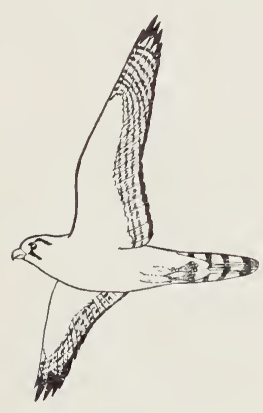

FALCONS

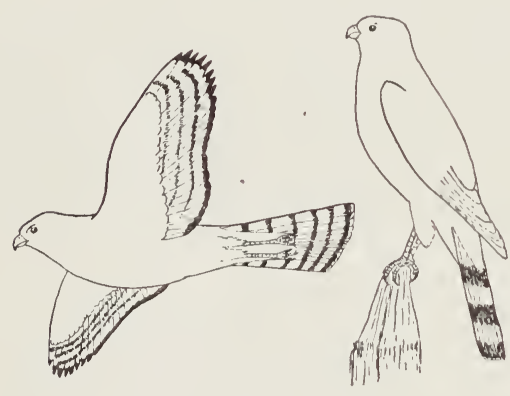

BULLET HAWKS
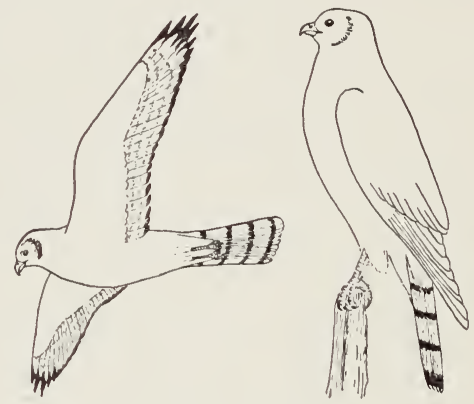

MARSH HAWK
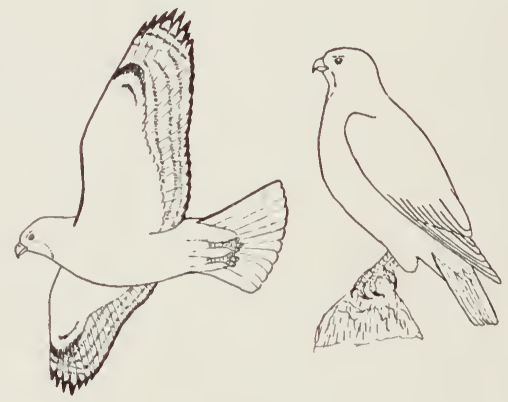

SOARING HAWKS

Fig. 24.-The four principal types of hawks are most casily recognized by the following characters, in flight. Falcons: tail and wings long, wings sharply pointed. Marsh hawks: wings long, tail long and square-ended, rump white. Bullet or quail hawks: wings short and blunt, tail long. Soaring hawks: large, wings bluntly rounded, tail short and spreading. (Sketches by D. D. McLean.)

quate. An occasional "bad actor" may need attention, but, in general, the soaring hawks should be protected.

Falcons seldom take quail. The smaller species, namely the sparrow hawk and pigeon hawk, feed primarily on insects, mice, and small birds. The larger duck hawk and prairie falcon are both birds of the open plains; their birdeating propensities are directed against high-flying types, which they strike on the wing with a sudden aerial dive or "stoop." Quail seldom expose themselves to such hunting, although an individual may occasionally be knocked out of a flying covey. These two large falcons are not common over valley quail range except in the inner Coast Range bordering the San Joaquin Valley. 
The manager can protect quail from hawks by providing more and better escape cover and by controlling the few harmful species. Of the two methods, the former not only protects quail, but permits the continued services of valuable rodent-hunting hawks. Within the limits imposed by habit, hawks take whatever prey is most readily available. Any improvement in the escape cover that protects quail will force hawks to seek other prey. Control by shooting is valuable when restricted to the species which are destructive, or to exceptional individuals among the beneficial types of hawks.

The bullet hawks and the duck hawk are the only hawks that are not protected under Section 1175 of the Fish and Game Code of the State of California. Normally, permission must be obtained from the Division of Fish and Game to kill legally any other hawk species. All owls, except the horned owl, are also protected.

The use of "pole-traps" for trapping or killing hawks and owls is prohibited by Section 1155 of the Fish and Game Code (24). This is a wise provision, since beneficial predators usually suffer more than harmful ones and since many valuable birds, including valley quail, are caught in pole traps as a result of their habit of using elevated lookout perches.

Owls.-Being night hunters, owls (fig. 25) feed primarily on the small mammals which are active after dark. The only owl that preys on quail to an appreciable extent is the horned owl, which forages at twilight, when quail are going to roost, and sometimes on rainy or cloudy days. Observations on this owl show that quail are generally snatched while settling for the night in their roosting trees. Improving the roosting cover should aid in protecting the quail. The killing of horned owls resident on quail ranges is recommended; shooting is the most practical method.

Other Birds.-Jays, being noisy, aggressive, and intimately associated with quail, are commonly accused of destroying the eggs and chicks; but reliable records of such damage are rare. In one quail-nesting study in jay country, 2 of the 55 nests destroyed by predators were attributed to jays. Actually, the jays may be of some value-at the approach of a common enemy, their noisy alarm notes will put a covey on the alert; and the jays aid in cracking acorns which may serve for quail food. The manager must evaluate the total effect of the jays before undertaking control.

Roadrunners occasionally catch and eat flightless quail chicks. They are of minor importance in the northern part of the state, but where common, particularly in the drier areas and deserts, it may occasionally be desirable to request permission to shoot them. (They are protected under the provisions of Section 1175 of the Fish and Game Code.)

Crows, ravens, magpies, and shrikes attack quail nests and chicks in a few areas, but their importance is slight. Control should be attempted only in special cases.

Ants.-These, particularly the red fire ant (Solenopsis), may be highly destructive in quail nests at hatching time. They are attracted by any odors of flesh and may discover and invade a nest just as the chicks start to pip the eggs. A swarm will destroy and eat an entire clutch of eggs as the breaking of the shells allows them entrance. Mother quail, remaining in an invaded nest, often become literally covered with ants. No general control methods are 
known; but where trouble is anticipated, any of the contact ant powders dusted in a wide ring around the nest a few days before hatching will give the needed protection.

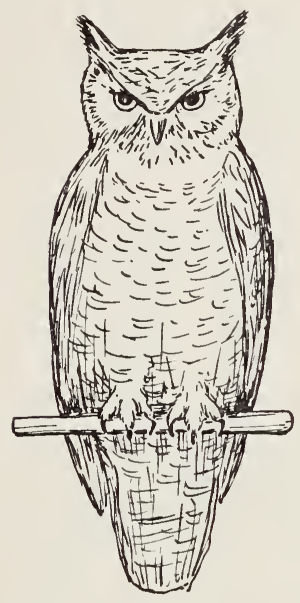

HORNED

OWL

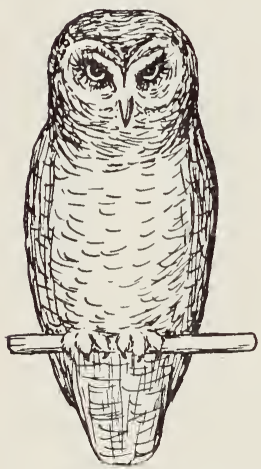

SPOTTED OWL

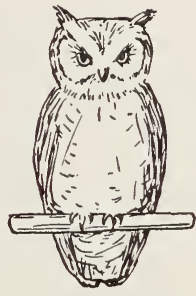

SCREECH

OWL

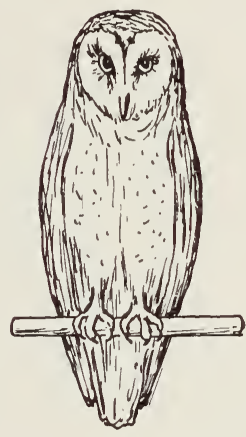

BARN OWL
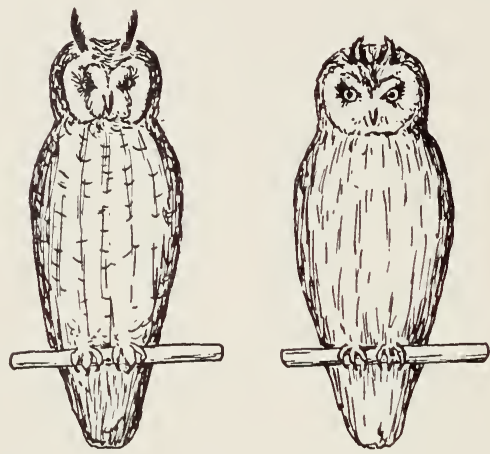

LONG-EARED OWL
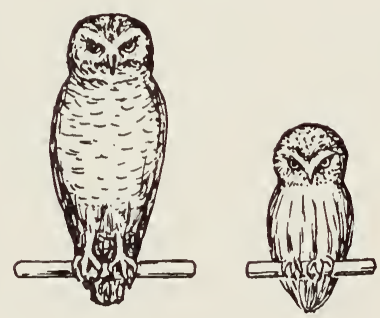

BURROWING OWL

\section{SHORT-EARED} OWL

Fig. 25.-Of the various species of owls in California, only the horned owl is a serious predator on valley quail. The others are all allies of the game manager in the control of rodents. (Sketches by Emily P. Thompson.)

\section{DISEASES AND PARASITES}

According to recent studies, parasitic diseases, such as bird malaria, coccidiosis, and intestinal worms, are common among wild valley quail in California; their exact significance for quail mortality, however, is incompletely understood. Seriously diseased quail are rarely encountered in the field, but this 
fact could readily be attributed to the secretive habits of sick birds and does not necessarily indicate a scarcity of victims. Where quail populations have been studied in detail, nearly all the losses can be attributed to predators or accidents, but it is impossible to say how many cases of predation may be associated with a preliminary weakening by disease.

Though almost nothing is known about the control of diseases in free-living wild quail, much work is now in progress. Sportsmen can assist in these studies by reporting outbreaks and, where possible, by sending sick or dead birds found in the field to the disease-study laboratories of the California Division of Fish and Game, Ferry Building, San Francisco. Dead birds should be packed in dry ice or in borax powder, to prevent spoilage during shipment. All such packages should be labeled as to contents and shipped by the fastest means; spoiled carcasses are of little value in disease studies.

\section{ACCIDENTS}

Accidents, whether natural or man-caused, destroy many quail each year. Much of this waste can be avoided by proper management and planning.

Farming operations are often dangerous to the birds. Mowing, the foremost cause of nest destruction with pheasants, only occasionally affects quail, since they do not regularly nest in open fields. A flushing bar, however, may save many quail nests along field borders and roadsides when these sites are being mowed. Late-spring and summer cultivation of vineyards and the borders of orchards and fields destroys many nests and baby chicks. The alert driver of a tractor or team can often locate a nest as the parent bird flushes and, by carefully steering around it, leave an "island" for protection. If possible, such islands of cover should be at least 10 feet in diameter.

Irrigation waters flood out many nests in fields, orchards, and irrigated pastures. Quail stand considerable wetting, but will almost invariably desert a nest if water actually enters, even for a brief period. Chicks can generally escape to high ground, but a narrow levee is not a safe refuge for them. Large irrigation ditches are death traps for young quail attracted to the water but unable to climb the steep banks or avoid the swift-flowing stream.

The use of poisons in pest control often destroys quail and other valuable animals incidentally. Dangers attendant on the use of thallium and other metallic poisons against rodents have already been mentioned. In citrus orchards, quail sometimes are killed by the standard practice of fumigating the trees with cyanide for insect pests. This work is usually done at night, and some roosting quail are trapped under the canvas tents used to retain the gas. Many orchardists flush the roosting birds from a tree before covering it.

Grazing cattle and sheep occasionally trample nests or, aroused by curiosity, nuzzle them apart. In one study on moderately grazed cattle range, 3 of the 55 nests destroyed were attributed to cattle. Excluding livestock during the nesting season is the only remedy that can be suggested. Complete exclusion of cattle, however, is not always desirable, for the stand of long grass which results is not good nesting cover. In Madera County, ungrazed pastures often supported less quail than those moderately grazed. Sheep are far more injurious than cattle because their close feeding destroys much quail food and cover. They should be restricted on quail-management areas wherever possible. 
Collisions of flying quail with man-made structures are relatively unavoidable. Wire fences cause many deaths, particularly among young, inexperienced birds. Windows and even white or aluminum-painted walls are at times struck during flight, with fatal results. Highway mortality is often a considerable factor. Collision mortality can be lessened on managed areas by locating food and cover developments away from hazardous structures.

Fire can be a serious enemy of valley quail. Uncontrolled burning is a menace because extensive, and hotly burning brush fires destroy many of the birds that are reluctant to leave their home territories. Controlled spot burning is not dangerous and may eventually become a cover-management tool. Every precaution should be taken to prevent accidental fires on a quail area.

Drought is another serious problem. Valley quail require drinking water in the dry season; and when water becomes scarce they either succumb or crowd together at the remaining sources, where predation and disease may be serious. There is also some indication that extremely dry summers result in a poor hatch of young. Maintaining adequate quail-watering installations will offset the bad effects of drought.

Storms, especially snowstorms that hide the essential food supplies, are sometimes extremely destructive, and emergency feeding stations are recommended in areas where such storms are to be expected. Light rains may harm newly hatched chicks, although this factor has been grossly exaggerated by popular writers. Floods cause much damage to quail habitat in some regions and, in spring, may wash out all nests in their path.

\section{HUNTING}

In evaluating the mortality factors acting on a quail population, we cannot overlook hunting, legal and otherwise.

In the past, certain favorable areas in California were centers for market hunting, and many thousands of quail were taken from a relatively few localities. When the supply of birds was reduced in one place, the market hunters merely moved on. This destructive practice was stopped by law in 1915. The severe local damage done before this date has probably left no permanent effect, for a decimated population of quail can quickly breed up to its former numbers when the pressure of excessive hunting is relieved.

At present, quail hunting is the sport of thousands : the California Division of Fish and Game estimates that about 1,200,000 quail are killed legally in California each year. Unfortunately, this kill is not well distributed; it tends to be concentrated or excessive close to cities, a condition made worse with the "posting" of much good quail range by unsympathetic landowners. To remedy this uneven distribuiton of hunting pressure and the resultant overshooting of some areas is a primary concern of modern quail management. The manager of a quail area must study the problem of hunting control.

\section{HARVESTING THE QUAIL CROP}

\section{HOW MUCH TO HARVEST}

Readers of this publication will have various reasons for wishing to encourage quail on their lands. Some are interested only in the esthetic charm of the birds and will wish to leave all quail unmolested; others are concerned pri- 
marily in the sport of shooting a fine game bird. This chapter is written for the latter group. For them, a careful plan of hunting regulation should be an integral part of the management program.

Because of the high breeding rate of quail, it is often possible to shoot a considerable portion of the autumn population without harm to the breeding stock essential for the next spring. In a healthy population, a surplus above the carrying capacity of the range usually exists in the autumn. This surplus may be safely shot, for it represents birds that would otherwise be removed by natural causes during the winter.

On many unmanaged ranges, hunting annually removes 10 to 25 per cent of the quail without bad effect. On one intensively managed area, a kill averaging about 25 per cent was taken every year for seven years; yet at the end there were more birds than at the start. It is dangerous, however, to generalize ; the percentage that may be taken must be determined by the local situation. Methods for measuring quail populations and surpluses are described later in this chapter.

\section{HOW TO HARVEST}

The objective of a quail program is primarily sport, not "meat-hunting;" every effort should be made to get the greatest possible amount of sport from the hunting. "Pot shooting" is an unfortunate use of valuable game. It is fostered by heavy concentrations such as those about watering places. The legal shooting season in California is purposely delayed until the early rains have dispersed the quail from their summer watering holes; but in some years these rains do not come until after the opening of the hunting season. In such years the manager may well delay hunting on his area to avoid the wastage of birds by shooters who cannot resist the temptation to "ground sluice." The liunting pressure should be well distributed over each area, and conveniently situated coveys should not be unduly harried or shot out.

Every quail hunter knows that when he brings home 10 birds, he has left a number of dead or badly wounded quail in the field. Questioning of hunters as they return from the field indicates that an average of about 6 quail are lost for every 10 bagged.

There are two practical ways of reducing this loss : first, to impress on hunters the need to pick up each bird as it is shot before shooting any more; and second, to insist that each man use a good retrieving dog on every hunt (fig. 26). On one area hunters not using dogs lost about 5 birds for every 10 brought home, whereas those with dogs lost less than 2 per bag of 10. More emphasis should be placed on the retrieving ability of dogs and less on their "range," or skill in locating coveys.

Quail need some respite from the guns during the hunting season. Continuous shooting, day after day and from dawn till dusk, interferes with their normal feeding and may cause them to lose weight. Quail may even be driven from their home ranges into areas of inferior cover. For these reasons, rest days should be provided during the open season; not more than two successive days of hunting should be allowed on any one area. Wednesdays, Saturdays, and Sundays are suggested as good shooting days. 


\section{HOW TO RECORD THE HARVEST}

To gauge how many quail may be safely removed from an area, the manager must have some measure of the number present. This measurement of the population also serves as a basis for evaluating the efficiency of the methods employed; it is fundamental to organized management.

A good quail census requires intensive field work by a careful observer ; it cannot be done from an easy chair. The methods described below have succeeded in a variety of situations.

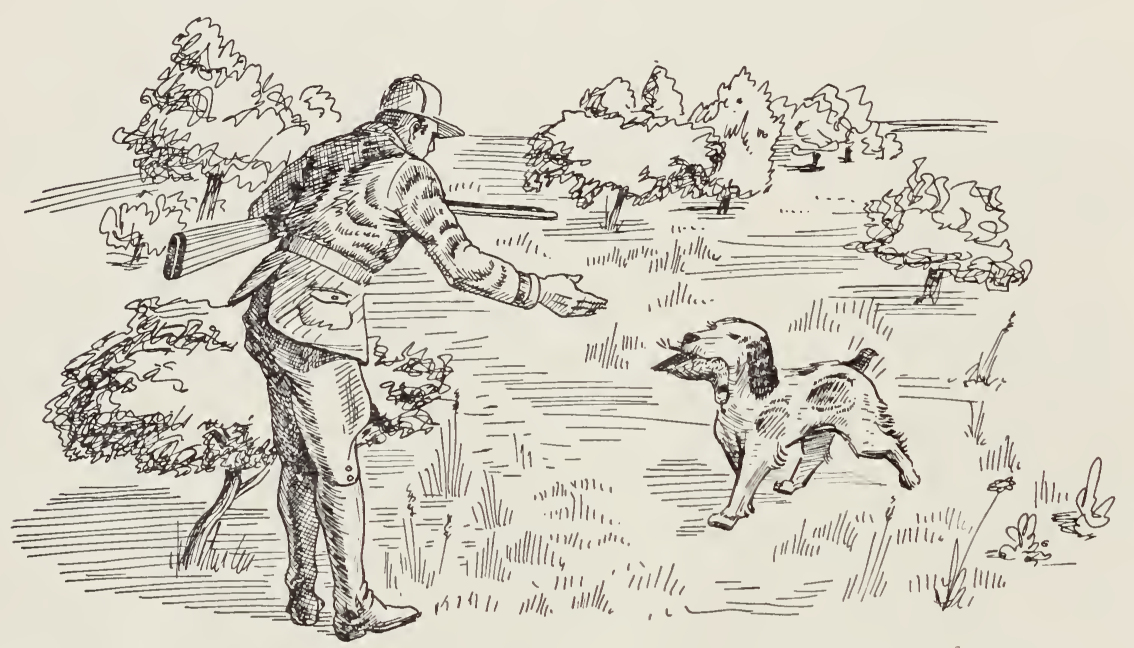

Fig. 26.-A retrieving dog will bring to the hunter's bag many quail that otherwise would be lost.

Where birds are all concentrated about watering holes in early autumn, a fair estimate of the hunting-season population can be obtained by making actual counts of the quail as they come to the water, and allowing a 7 per cent loss per month until the opening of the season.

In areas where quail have separate, well-defined covey ranges in winter, one may tabulate all coveys, listing the number of birds in each. A good bird dog can be used to advantage in this type of census. These counts should be made on days that are not excessively hot, rainy, or windy, since in such weather the birds remain close to their loafing cover, from which they are not easily flushed. Where bullet hawks are common, many quail will be missed, since they will not leave cover in the presence of these hawks.

On areas where covey ranges regularly overlap, the census must be taken in a different way. In relatively open country, the horseback method is recommended (5). Two to four riders, arranged side by side and spaced about 200 feet apart (fig. 27), cover the area as a unit in much the same manner as a man mowing a lawn; when the riders reach the end of a strip, they wheel about, pivoting on the outside man, and return on the adjacent strip. This procedure is followed over the entire area. Three men can cover about 1,000 acres per day on flat lands or low hills with scattered cover. 
Where a ranch of many thousand acres is to be censused, it is best to count the quail on several scattered sample strips, estimate the acreage covered, calculate the number of birds seen per acre, and then multiply this figure by the total number of acres on the ranch.

Where the brush is too thick to permit a satisfactory count by coveys or on horseback, the number of birds can be estimated by the "visual Lincoln index." A sample of the population is trapped, marked with colored celluloid bands, and then released. A few days later the covey is watched through field glasses, and the ratio of marked quail seen to the total number seen is noted. This ratio should be the same as that between the total number of marked birds

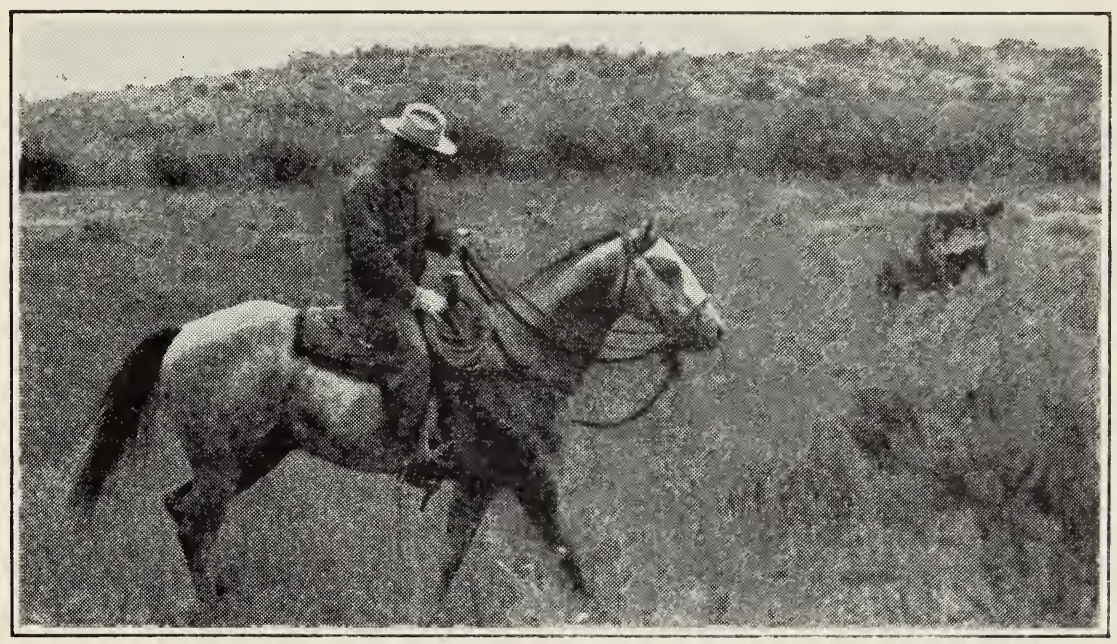

Fig. 27.-Quail may be counted in relatively open country by means of a horseback census.

(known) and the total quail population of the area (the desired unknown). Only an experienced person can make this type of census, and he must obtain a permit from the Division of Fish and Game before trapping any birds.

A similar census may be made by trapping and marking a number of quail just before the hunting season. Then, during the annual shoot, the ratio of marked birds shot to the total shot will, when divided by the number of birds marked, give a figure for the total population. The percentage of bands returned is roughly the percentage of kill.

One way of evaluating the success of a management program is to keep notes on changes in the ratio of old and young birds. In early summer the manager should record the number of chicks present in broods of all sizes and should compare his total counts of chicks and immature birds with the number of old quail seen. These "old-young" ratios, repeated annually, will give a relative picture of the degree of nesting success and of fledgling survival in each year.

During the hunting season, records should be kept of the number of young of the year and of full adults in the bags. Birds in their first year may be distinguished from older quail by the presence of white or buff tips on the small 
feathers (primary wing coverts) that cover the bases of the large outer wing feathers (primaries). In old birds the small feathers are solid gray (fig. 28). This characteristic is easily learned and gives the manager a clue to nesting success and seasonal mortality. Age ratios are usually expressed as young per 100 adults. In general, a high ratio of young in a population indicates a good nesting and rearing season.

On a well-managed range, hunters should make reports at the end of each day. A sample record card is shown on the following page. Compiling and studying the data obtained from such cards will give the manager many important bits of information, including a measure of hunter success.

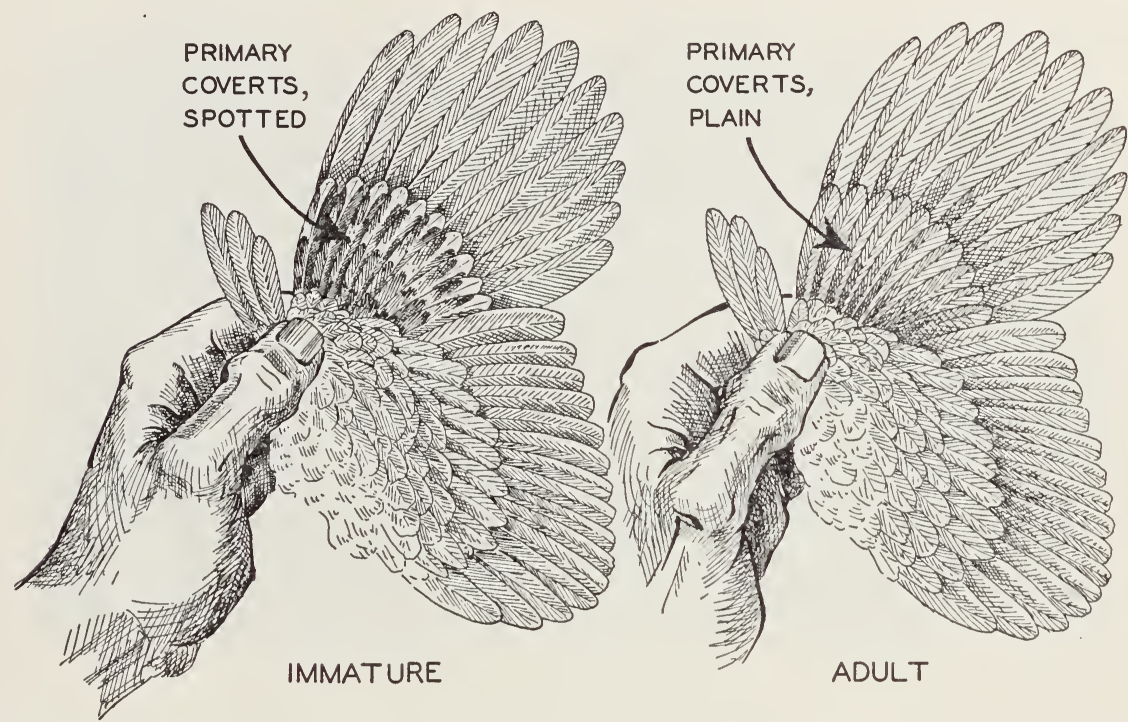

Fig. 28.-Determining the age of quail by examining the small feathers (primary coverts) over the main flight feathers (primaries) on the outer surface of the wing. The small group of feathers (bastard wing) at the front margin of the wing should be held aside to see the age character. The primary coverts are uniform in color in adults; in immature birds they are spotted.

In deciding how many hunters to allow on an area, the manager should know the approximate number of quail present when the season opens. He should also have a measure of local hunter success, which depends on shooting skill, the type of range, and on the number of birds present. On unmanaged foothill range lands the average sportsman gets about 6 quail per day in the field. For the first year of shooting on an area, the kill should be about 20 per cent of the total population prior to hunting season. If the hunter success is 6 quail per day, the manager should divide this 20 per cent figure by 6 to determine how many sportsmen can be safely admitted to the area. In succeeding years, if the quail population increases, the manager may slowly raise the annual take as long as he has proof that he is not damaging the breeding stock.

Much other valuable information may be gathered from a study of the daily reports by hunters. The purposes that such data may serve are limited only by the imagination of the individual manager. 


\section{SMITH RANCH QUAIL-HUNTING AREA}

Name of hunter.

Date. .

Started to hunt. a.m.

p.m.

Dog used?.

Stopped hunting

a.m.

Total hunting time.

hours

minutes

\section{Coveys hunted \\ (name or location of covey)}

Number of birds taken from each In the bag Crippled or lost

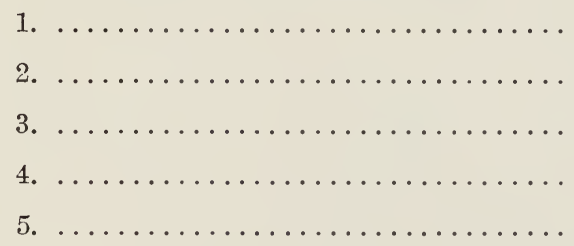

Totals

Adult males

Immature males.

Total males.

Adult females.

. Immature females

Total females.........

Total adults.

Total immatures..........

Type of gun (double, pump, automatic)

Bore. .

.Number of shells used.

Banded quail taken

Band number

Where taken

1.

2.

3.

4.

5 .

6.

\section{HUNTING PRIVILEGES AND RIGHTS}

According to American hunting law, the right of allowing trespass on any private land is vested in the landowner or lessee; and the title to game belongs to the public. The laws are so interpreted that the public, in order to hunt on privately owned land, must first get permission from the landowner or lessee. In California, common disregard for this requirement has led to many areas 
being closed to hunting. In some counties, up to 90 per cent of the quail lands are "posted," so that much of the public's game is locked up. Sportsmen and their organizations should endeavor to open this vast reservoir so that the pressure of hunting may be more evenly distributed.

Opening of these posted lands will not be accomplished by changing the basic legal concepts; the property owners have a legitimate case. Success can be achieved only by fostering coöperation between hunters and landowners.

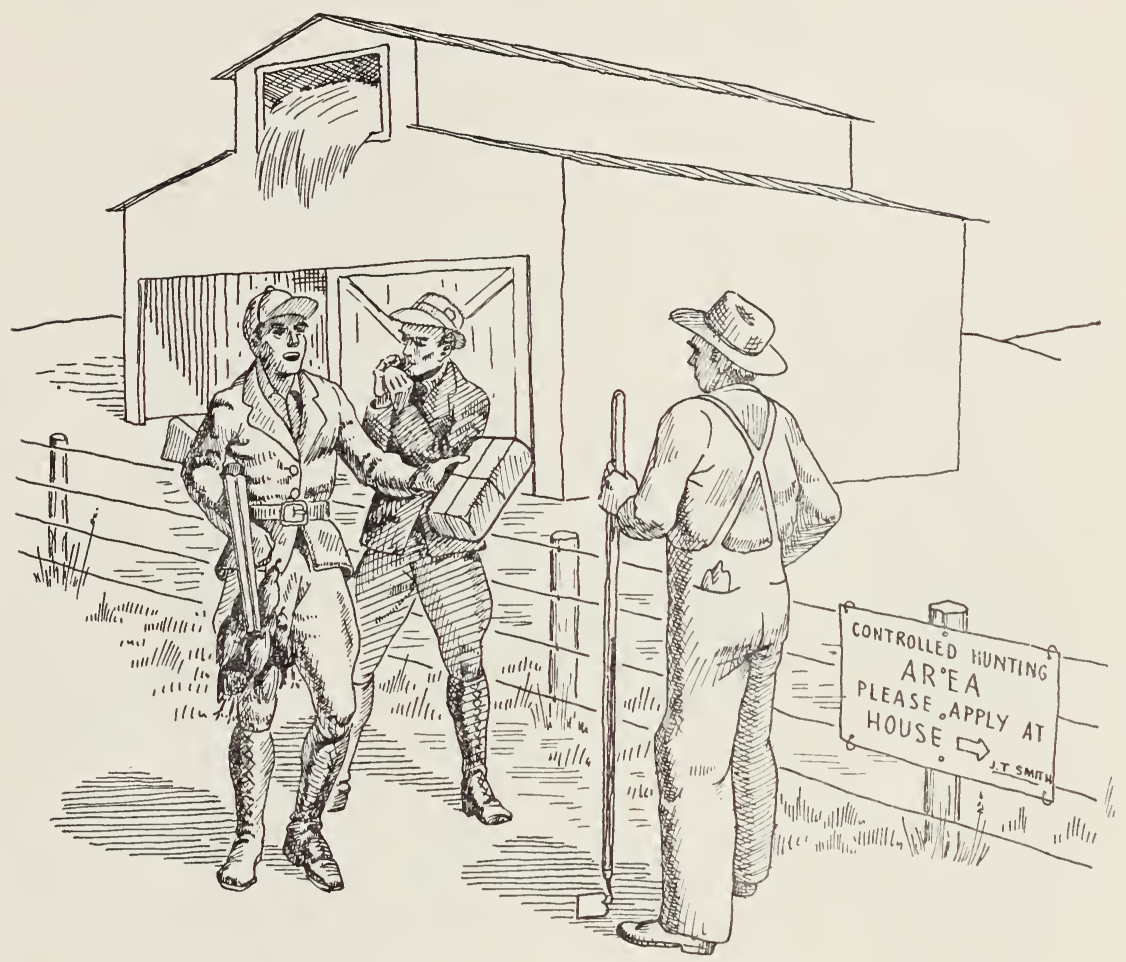

Fig. 29.-By establishing friendly relations with ranchers, sportsmen may ensure hunting grounds for themselves.

Sportsmen, through careless disregard for property, have been responsible for much of the trouble; and the first move toward coöperation must come from them. At present, the approach must be made by individuals or local groups rather than by statewide organizations. The types of owner-sportsmen coöperation outlined below are already widely used in duck hunting; but only a small start has been made on upland game areas in California.

The least expensive and simplest way for a hunter to obtain access to quail lands is to make a personal arrangement with some rancher. He should have something to offer in exchange for shooting privileges. He may help with the crops, or conduct year-round predator and rodent control to the mutual advantage of the rancher and himself. If in these or in other ways suggested by the individual situation, he can be of aid, he will be a welcome guest and not a nuisance on the opening day of quail season (fig. 29). 
Such arrangements do not often provide opportunities for habitat improvement or general quail management. Perhaps the best way to obtain satisfactory management and shooting control is to buy the land. Usually, however, the pleasure derived will not justify the cost. Then, too, other values, such as erops and livestock, must be considered. Not many sportsmen are equipped to manage a large herd of cattle in order to defray the expense of a few weeks of shooting.

On many range lands and on some farm lands the rancher, if convinced that he is dealing with responsible parties, will lease the shooting rights for a reasonable sum. The lease should provide for a management program. Agreements often can be made of mutual benefit in arranging for equipment, labor, and materials.

Shooting-right agreements may be made by individual hunters or, if the ranch be large enough, by groups. There is no better way for a sportsmen's club to expend its energies throughout the year than to work with a rancher toward providing a large and healthy quail population. Such work will give a maximum return in sport for a minimum outlay in money.

Some ranchers, whether or not they hunt quail themselves, will want to benefit by the birds shot on their properties. While they are not permitted to sell game as such, they are entitled to charge for trespass rights. Obviously the rancher who has no quail will have no customers. To make a popular shooting ground of his area, the rancher must use some portion of his gross earnings from shooting rights for habitat improvement and game protection. If he does this well, he will attract a coöperative and helpful group of sportsmen customers.

Where property holdings are small, several farmers may combine to form a sizable hunting area and act as a unit in coöperating with a sportsmen's group. This plan has worked satisfactorily in several midwestern states.

In the future, some way may be found for the State to bring ranchers and sportsmen together. Until then, sportsmen can proceed on their own initiative to gain the confidence and friendship of landowners. As coöperative groups obtain management privileges on game areas and begin constructive work, they will find as much pleasure in developing game populations as in hunting them.

1. Bent, A. C.

\section{LITERATURE CITED}

1932. Life histories of North American gallinaceous birds. U. S. Natl. Mus. Bul. 162 (pt. XI) :1-490. Illus.

2. EMLen, J. T., JR.

1939. Seasonal movements of a low-density valley quail population. Journal of Wildlife Management 3:118-30.

3. EMLEN, J. T., JR.

1940. Sex and age ratios in survival of the California quail. Journal of Wildlife Management $4: 92-99$.

4. Glading, Ben.

1938. Studies on the nesting cycle of the California valley quail in 1937. California Fish and Game $24: 318-40$.

5. Glading, Ben.

1941. Valley quail census methods and populations at the San Joaquin Experimental Range. California Fish and Game 27:33-38. 
6. Glading, Ben.

1943. A self-filling quail watering device. California Fish and Game 29:157-64.

7. GLading, Ben.

1943. A bee repellent for use in quail watering devices. California Fish and Game 29: 165-67.

8. Glading, Ben., H. H. Biswell, and C. F. Smith.

1940. Studies on the food of the valley quail in 1937. Journal of Wildlife Management $4: 128-44$.

9. Grange, W. B., and W. L. McAtee.

1934. Improving the farm environment for wildlife. U. S. Dept. Agr. Farmers' Bul. 1719:1-61. 20 fig.

10. Grinneli, J., H. C. Bryant, and T. I. Storer.

1918. The game birds of California. 642 p. 16 pl. 94 fig. University of California Press, Berkeley, California.

11. HAWBECKER, A. C.

1940. Planting for California wildlife. California Fish and Game 26:271-77.

12. Howard, W. E., and J. T. EMLEN, JR.

1942. Intercovey social relationships in the valley quail. The Wilson Bulletin 54:16270.

13. LEHMAN, V. W.

1937. Increase quail by improving their habitat. 44 p. Illus. Texas Game, Fish and Oyster Commission. Austin, Texas.

14. LeOPOLd, Aldo.

1933. Game management. 481 p. 35 fig. Chas. Scribner's Sons, New York, N. Y.

15. McLean, D. D.

1930. The quail of California. California State Dept. Nat. Resources, Div. of Fish and Game, Game Bul. 2:1-47.14 fig.

16. RAHM, N. M.

1938. Quail range extension in the San Bernardino National Forest-progress report, 1937. California Fish and Game 24:133-58.

17. Richardson, Frank.

1941. Results of the southern California quail banding program. California Fish and Game 27:234-49.

18. Stoddard, H. L.

1932. The bobwhite quail, its habits, preservation and increase. 559 p. 59 pl. 32 fig. Chas. Scribner's Sons, New York, N. Y.

19. STORER, T. I.

1942. Control of injurious rodents in California. California Agr. Ext. Cir. 79:1-66. 29 fig.

20. Sumner, E. L., JR.

1935. A life history study of the California quail with recommendation for conservation and management. California Fish and Game 21:165-256, 277-342.

21. SWingle, C. F.

1939. Seed propagation of trees, shrubs, and forbs for conservation planting. U. S. Dept. Agr. Soil Conserv. Serv. SCS-TP-27. 198 p. Illus.

22. VAN DERSAL, W. R.

1939. Native woody plants of the United States; their erosion control and wildlife values. U. S. Dept. Agr. Mise. Pub. 303:1-362. Illus.

23. WIGHT, How ARD.

1939. Field and laboratory technique in wildlife management. 107 p. Illus. University of Michigan Press, Ann Arbor, Mich.

24. Wight, H. M.

1931. The effect of pole traps on harmless and beneficial species. The Wilson Bulletin $43: 282-92$. 